\title{
Long-Term, Targeted Delivery of GDNF from Encapsulated Cells Is Neuroprotective and Reduces Seizures in the Pilocarpine Model of Epilepsy
}

\author{
Giovanna Paolone, ${ }^{1,3}$ Chiara Falcicchia, ${ }^{1,3}$ Francesca Lovisari, ${ }^{1}$ Merab Kokaia, ${ }^{2}$ William J. Bell, ${ }^{3}$ Tracie Fradet, ${ }^{3}$ \\ Mario Barbieri, ${ }^{1}$ Lars U. Wahlberg, ${ }^{3}$ Dwaine F. Emerich, ${ }^{3}$ and Michele Simonato ${ }^{1,4,5}$ \\ ${ }^{1}$ Department of Medical Science, Section of Pharmacology, Neuroscience Center, University of Ferrara and National Institute of Neuroscience, 44121 \\ Ferrara, Italy, ${ }^{2}$ Epilepsy Centre, Department of Clinical Sciences, Lund University Hospital, 22100 Lund, Sweden, ${ }^{3} \mathrm{Gloriana}$ Therapeutics, Inc. (formerly \\ NsGene Inc.), Providence, Rhode Island 02905, ${ }^{4}$ Laboratory of Technologies for Advanced Therapy (LTTA), Technopole of Ferrara, 44121 Ferrara, Italy, \\ and ${ }^{5}$ School of Medicine, University Vita-Salute San Raffaele, 20132 Milan, Italy
}

Neurotrophic factors are candidates for treating epilepsy, but their development has been hampered by difficulties in achieving stable and targeted delivery of efficacious concentrations within the desired brain region. We have developed an encapsulated cell technology that overcomes these obstacles by providing a targeted, continuous, de novo synthesized source of high levels of neurotrophic molecules from human clonal ARPE-19 cells encapsulated into hollow fiber membranes. Here we illustrate the potential of this approach for delivering glial cell line-derived neurotrophic factor (GDNF) directly to the hippocampus of epileptic rats. In vivo studies demonstrated that bilateral intrahippocampal implants continued to secrete GDNF that produced high hippocampal GDNF tissue levels in a long-term manner. Identical implants robustly reduced seizure frequency in the pilocarpine model. Seizures were reduced rapidly, and this effect increased in magnitude over 3 months, ultimately leading to a reduction of seizures by $93 \%$. This effect persisted even after device removal, suggesting potential disease-modifying benefits. Importantly, seizure reduction was associated with normalized changes in anxiety and improved cognitive performance. Immunohistochemical analyses revealed that the neurological benefits of GDNF were associated with the normalization of anatomical alterations accompanying chronic epilepsy, including hippocampal atrophy, cell degeneration, loss of parvalbumin-positive interneurons, and abnormal neurogenesis. These effects were associated with the activation of GDNF receptors. All in all, these results support the concept that the implantation of encapsulated GDNF-secreting cells can deliver GDNF in a sustained, targeted, and efficacious manner, paving the way for continuing preclinical evaluation and eventual clinical translation of this approach for epilepsy.

Key words: cell therapy; epilepsy comorbidity; GDNF; neurodegeneration; neuroprotection; temporal lobe epilepsy

Significance Statement

Epilepsy is one of the most common neurological conditions, affecting millions of individuals of all ages. These patients experience debilitating seizures that frequently increase over time and can associate with significant cognitive decline and psychiatric disorders that are generally poorly controlled by pharmacotherapy. We have developed a clinically validated, implantable cell encapsulation system that delivers high and consistent levels of GDNF directly to the brain. In epileptic animals, this system produced a progressive and permanent reduction $(>90 \%)$ in seizure frequency. These benefits were accompanied by improvements in cognitive and anxiolytic behavior and the normalization of changes in CNS anatomy that underlie chronic epilepsy. Together, these data suggest a novel means of tackling the frequently intractable neurological consequences of this devastating disorder.

\section{Introduction}

Epilepsy affects tens of millions of individuals across all ages, ethnic groups, and social classes. A significant portion of epilep- sies in adults originate focally from mesial temporal lobe structures that include the hippocampus, entorhinal cortex, and

This research was supported by a grant from the European Community FP7-PEOPLE-2011-IAPP 536 project 285827 (EPIXCHANGE) to M.S. and L.U.W.

L.U.W. and D.F.E. are employees of Gloriana Therapeutics, Inc., a for-profit biotechnology company that is developing the encapsulated cell technology to treat CNS diseases. The authors declare no other competing financial interests. 
amygdala (Stephen and Brodie, 2000; Sridharan, 2002). These so-called mesial temporal lobe epilepsies (mTLEs) cannot be cured, and the currently available pharmacological options cause significant unwanted side effects and are ineffective in up to onethird of the patients (Kwan and Brodie, 2000; Engel et al., 2012). These patients continue to experience seizures, and, in many cases, their seizures increase in frequency and are associated with significant cognitive decline and psychiatric disorders (Aldenkamp and Arends, 2004; Lin et al., 2012; Nogueira et al., 2017). The focal nature of mTLE opens the opportunity for direct therapeutic options including surgery, local radiation, and deep brain stimulation. More recently, gene therapy has emerged as a possible means of direct, local delivery of potentially therapeutic agents such as trophic proteins to the temporal lobe (Simonato et al., 2013). Gene therapy typically involves injecting a viral vector into the desired site to transduce local cells for producing the desired agent and achieving localized high levels of the agent itself (Kanter-Schlifke et al., 2009; Eriksdotter-Jönhagen et al., 2012; Tornøe et al., 2012; Nikitidou et al., 2014; Ledri et al., 2016). While promising, the limitation of this approach is its permanent, irreversible, and nonregulatable nature. Nonetheless, several studies have provided compelling proof of concept for these approaches in TLE (Simonato, 2014).

Recently, glial cell line-derived neurotrophic factor (GDNF) has emerged as a potential antiepileptic candidate. GDNF and its receptor are expressed within the temporal lobe, particularly the pyramidal and granule cells of the hippocampus. An association between GDNF and epilepsy is suggested by the observations that (1) seizures increase the expression of hippocampal GDNF mRNA and protein (Humpel et al., 1994; Kokaia et al., 1999) and (2) that chemically and electrically induced seizures can be suppressed by local infusion of GDNF or injection into the hippocampus of viral vectors expressing GDNF (Yoo et al., 2006; Kanter-Schlifke et al., 2007, 2009). Together, these data strongly indicate that locally increasing GDNF levels in the temporal lobe could represent a possible way of suppressing epileptic activity.

Here, we used an encapsulated cell approach for the delivery of GDNF (EC-GDNF) directly into the hippocampus of rats made epileptic by a systemic injection of pilocarpine. This approach is based on enclosing ARPE-19 cells genetically modified to secrete GDNF in an immunoprotective polymer membrane before transplantation (Fjord-Larsen et al., 2012; Tornøe et al., 2012; Emerich et al., 2014). Using this approach, we tested the following hypotheses: (1) that EC-GDNF can provide controlled, stable, and long-term delivery of GDNF to the hippocampus in a well tolerated manner; (2) that the targeted delivery of GDNF can elicit a significant and long-lasting reduction of pilocarpineinduced seizures while normalizing changes in anxiety and cognition; and (3) that these functional benefits are associated with improvements in quantifiable immunohistochemical indices of hippocampal morphology. The present findings are the first to demonstrate that encapsulated GDNF-secreting cells produce long-term and robust elevations in hippocampal GDNF that are well tolerated, efficacious, and perhaps disease modifying across a spectrum of epilepsy-relevant neurological measures. In addition, these neurological benefits were associated with GDNF receptor engagement and normalization of hippocampal morphology, Fluoro Jade C (FJC)-positive cells, neurogenesis, and the number of parvalbumin-expressing GABAergic neurons.

Correspondence should be addressed to Giovanna Paolone at giovanna.paolone@univr.it.

https://doi.org/10.1523/JNEUROSCI.0435-18.2018

Copyright $\odot 2019$ the authors $\quad 0270-6474 / 19 / 392145-13 \$ 15.00 / 0$

\section{Materials and Methods}

Animals. Experiments were performed on adult male Sprague Dawley rats (Harlan Laboratories) weighing 225-250 g upon arrival. Rats were housed in a temperature- and humidity-controlled colony room maintained on a $12 \mathrm{~h}$ light/dark cycle (lights on at 7:00 A.M.). Food and water were available ad libitum throughout the experiment. All procedures were performed in adherence with the guidelines of the National Institute of Health and the European Community (EU Directive 2010/63/EU) on the Use and Care of Animals. The approved protocol from the University of Ferrara Committee on Animal Welfare was authorized by the Italian Ministry of Health (D.M. 246/2012-B). Furthermore, the Animal Research: Reporting In Vivo Experiments guidelines (Kilkenny et al., 2011) and the recommendations for improving animal welfare in rodent models of epilepsy and seizures (Lidster et al., 2016) have been followed. Following pilocarpine treatment, animals were randomly assigned to the experimental or control group.

Cell culture. ARPE-19 cells were cultured using standard procedures in T-175 flasks with $1 \times$ DMEM-GlutaMAX growth medium supplemented with 10\% fetal bovine serum (catalog \#10566-016, Invitrogen). Routine culture consisted of feeding the cells every $2-3 \mathrm{~d}$ and passaging them at $70-75 \%$ confluence. Cells were incubated at $37^{\circ} \mathrm{C}, 90 \%$ humidity, and $5 \% \mathrm{CO}_{2}$.

Cell line establishment. We generated clonal GDNF-secreting ARPE-19 cell lines using the sleeping beauty (SB) transposon expression system (Fjord-Larsen et al., 2010, 2012). Briefly, ARPE-19 cells were cotransfected with the plasmid pT2.CAn.hopp. GDNF, containing the entire GDNF sequence, and the SB vector pCMVSB100X. clones were selected using G418 (Sigma-Aldrich), and single colonies were expanded and isolated based on their GDNF release levels. Clonal cell lines producing high and stable levels of GDNF were further characterized in vitro and in vivo, and the GDNF clone used in the experiments was selected based on high GDNF secretion and long-term function in devices in vivo.

Device fabrication. Cells were encapsulated into hollow fiber membranes as previously described (Tornøe et al., 2012). Devices were manufactured from $7 \mathrm{~mm}$ segments of polysulfone membrane internally fitted with filaments of polyethylene terephthalate yarn scaffolding for cell adhesion. Before filling, cultured cells were dissociated and suspended in human endothelial (HE)-SFM (catalog \#11111-044, Thermo Fisher Scientific), and $5 \times 10^{4}$ cells were injected into each device using a custom-manufactured automated cell-loading system. Devices were kept in $\mathrm{HE}-\mathrm{SFM}$ at $37^{\circ} \mathrm{C}$ and $5 \% \mathrm{CO}_{2}$ for $2-3$ weeks before surgical implantation. Devices loaded with nonmodified ARPE-19 cells were treated in the same manner and included as negative controls.

Surgical implantation and retrieval. In all efficacy studies, surgery for device implantation was performed $20 \mathrm{~d}$ after status epilepticus (SE), between two video monitoring sessions, as described below. Rats were placed into a stereotaxic instrument (Stoelting) and were continuously anesthetized with $1.5-2 \%$ isoflurane via a nose cone. Ophthalmic ointment was used to lubricate eyes. A midline incision was made in the scalp, and two bilateral holes were drilled through the skull. Devices filled with ARPE-19 GDNF cells or nonmodified ARPE-19 cells were bilaterally implanted into the hippocampus using a cannula mounted to the stereotaxic frame. The coordinates for implantation were as follows: anteroposterior (AP) $-4.8 \mathrm{~mm}$ mediolateral $(\mathrm{ML}) \pm 4.1$ with respect to bregma; and dorsoventral (DV) $-7.0 \mathrm{~mm}$ below dura (Paxinos and Watson, 2007). After placement of the device, the skin was sutured closed. Animals received a postoperative injection of amikacin $(250 \mathrm{mg} / \mathrm{ml}, 0.1$ $\mathrm{ml}$, i.p.) and buprenorphine $(0.01 \mathrm{mg} / \mathrm{kg} / \mathrm{ml}$, i.p.), and the incision site was treated with neosporin. For retrieval, devices were removed by placing the anesthetized animal into the stereotactic frame, visualizing the proximal tip of the implant, and gently removing it using microforceps.

Rats used for video-EEG monitoring (experimental group, $n=7$; control group, $n=5$ ) were implanted with a bipolar electrode (PlasticsOne) in the right dorsal hippocampus during the surgery session of the device implantation. The coordinates for electrode implantation were AP $-3.4 \mathrm{~mm}$ and $\mathrm{ML}-1.7$ with respect to bregma; and $\mathrm{DV}-3.5 \mathrm{~mm}$ below dura. The ground wire was connected to five screws secured to the skull, and the electrode was fixed with dental cement. 


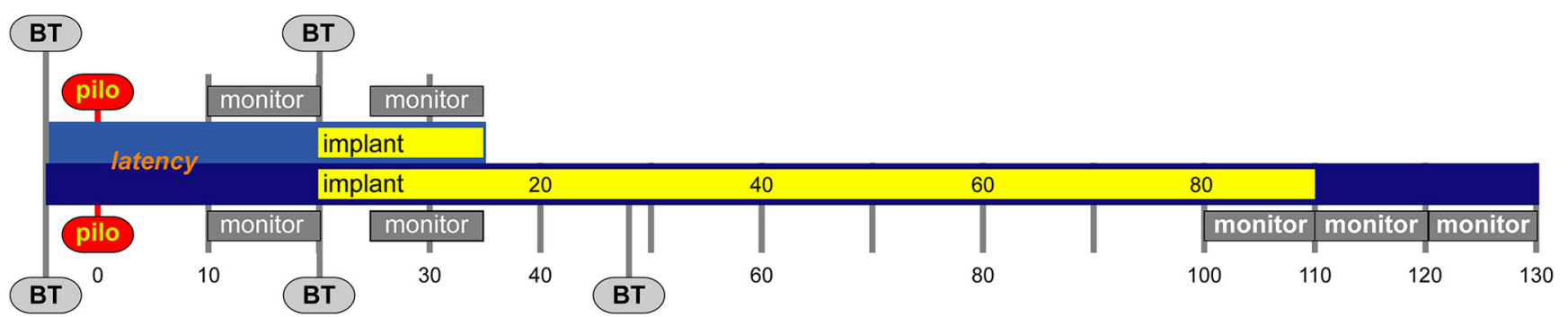

Figure 1. Experimental design. BT, Behavioral testing; pilo, pilocarpine.

ELISA. GDNF secretion from cell-loaded devices was verified before implantation and again following retrieval from the brain. Devices were incubated at $37^{\circ} \mathrm{C}$ in HE-SFM. Media samples ( $4 \mathrm{~h}$ incubation) were collected the next day to quantify GDNF release using a commercially available ELISA kit (DuoSet for human GDNF; catalog \#DY212, R\&D Systems). Previously implanted hippocampi were dissected free, transferred to vials containing $1 \mathrm{ml}$ of Tissue Protein Extraction Reagent (T-PER; catalog \#78510, Thermo Fisher Scientific), and flash frozen in liquid nitrogen. Supernatants from pulverized, and centrifuged tissue samples were assessed for GDNF levels using the ELISA kit mentioned above.

Long-term encapsulated cell function and tissue levels of GDNF in intact rats. We assessed the long-term (6 months) in vivo secretion of GDNF from cell-loaded devices, and the resulting levels of GDNF in the implanted hippocampi of intact rats (experimental group, $n=36$; control group, $n=4)$. Devices were implanted as described above, and were removed at 1,2, and 4 weeks postimplant, then monthly up to 6 months postimplant. The number of midline cage crossovers and the level of animal arousal were monitored for $60 \mathrm{~s}$ every $20 \mathrm{~min}$ for $2 \mathrm{~h}$, at each time point. Behavior was rated using a modified version of the scale of Ellinwood and Balster (1974) i.e., 1, asleep (lying down, eyes closed); 2, awake/inactive (lying down, eyes open); and 3, crossing (moving, sniffing, rearing). Body weights were monitored biweekly. Four normal, intact animals were used as controls at each time point.

Pilocarpine treatment. Pilocarpine ( $340 \mathrm{mg} / \mathrm{kg}$; catalog \#P6503, SigmaAldrich) was administered intraperitoneally $30 \mathrm{~min}$ after a single subcutaneous injection of methylscopolamine $(1 \mathrm{mg} / \mathrm{kg})$, and the behavior of the rats was monitored and rated for several hours thereafter, using the scale of (Racine et al., 1972; Curia et al., 2008), as follows: 1, chewing or mouth and facial movements; 2 , head nodding; 3 , forelimb clonus; 4 , generalized seizures with rearing; and 5 , generalized seizures with rearing and falling. Within the first hour after pilocarpine injection, animals developed seizures that evolved into recurrent generalized (stage 4 and higher) convulsions (SE). Of the 60 animals administered pilocarpine, 95\% (i.e., 57 animals) entered SE. SE was interrupted after $2 \mathrm{~h}$ by the administration of diazepam $(10 \mathrm{mg} / \mathrm{kg}$, i.p. $)$. Twenty animals died during SE or in the following $3 \mathrm{~d}$. Therefore, 37 animals were included in the study (allocation in the groups described below: 2 week implant experimental group, $n=9 ; 12$ week implant experimental group, $n=8$; control group, $n=8$; video-EEG monitoring: experimental group, $n=7$; control group, $n=5$ ).

Video monitoring of seizure activity. Pilocarpine-treated animals were continuously video recorded for the quantification of generalized (class 4 or 5) seizures (Fig. 1). At the end of the latent phase (i.e., following the first spontaneous seizure; $10 \pm 1 \mathrm{~d}$ after SE), the frequency and duration of generalized seizures were recorded through continuous video monitoring for $10 \mathrm{~d}$. Animals then received bilateral intrahippocampal implants of devices or devices plus electrodes, and video or video-EEG monitoring was resumed $5 \mathrm{~d}$ after implantation for an additional $10 \mathrm{~d}$. At the conclusion of monitoring ( $\sim 35 \mathrm{~d}$ post-SE), animals were anesthetized and the devices were retrieved for confirmation of GDNF secretion. In a separate experiment, we examined the long-term effects of GDNF device implantation on seizures as well as the persistence of these effects after the devices were removed. SE was induced as described above, and animals were randomly divided into the following two treatment groups: bilateral implants of GDNF devices or of control devices loaded with the nonmodified parental ARPE-19 cell line. Animals were then monitored, and the seizure frequency and duration were recorded for two $10 \mathrm{~d}$ periods (days 5-15 and days 80-90 postimplantation; Fig. 1). After the second monitoring session, the devices were removed and the animals were monitored for an additional $20 \mathrm{~d}$. At the conclusion of all experiments, hippocampi were removed and processed for quantification of GDNF levels.

For video-EEG monitoring, the rat headset was connected through a tripolar cable (PlasticsOne) to an EEG100C amplifier/MP150 Data Acquisition (Biopac) system, and signals were analyzed using AcqKnowledge version 5.0 software (Biopac). EEG seizures were defined as periods of paroxysmal activity of high frequency $(>5 \mathrm{~Hz})$ characterized by a more than threefold amplitude increment over baseline with progression of the spike frequency that lasted for a minimum of $5 \mathrm{~s}$ (Williams et al., 2009; Paradiso et al., 2011).

Open field arena and novel object recognition tests. The effects of GDNF on anxiety-like behavior and cognition were investigated using the open field (OF) and novel object recognition (NOR) tests, respectively (experimental group, $n=13$; control group, $n=14$ ). Each test was performed at the following three time points: before pilocarpine treatment (baseline); before device implantation ( 4 weeks after SE); and again 4 weeks after implant (Fig. 1). Before device implant, animals were randomly assigned to the following two groups: pilocarpine or pilocarpine + GDNF. For the OF test, animals were placed in an arena $(75 \times 75 \times 30$ $\mathrm{cm}$ ) and video monitored for $30 \mathrm{~min}$. Videos were analyzed (catalog \#60201, ANY-maze) for distance moved, immobility, entries, and time spent in the center part of the arena. For the NOR, rats were tested in three phases. In the habituation phase (day 1), animals were allowed to freely explore the arena for $30 \mathrm{~min}$. The following day, in the familiarization phase, rats were transferred for $5 \mathrm{~min}$ to the arena, where two identical objects were positioned in the central quadrant in opposite and symmetrical corners $(\mathrm{A}+\mathrm{A})$. In the testing phase ( $2 \mathrm{~h}$ later $)$, animals were returned to the arena with one of the objects replaced with a novel one $(\mathrm{A}+\mathrm{B})$. The time spent exploring the objects was recorded by a blind investigator. To control for seizure effects in behavioral performance, rats were always tested at least $2 \mathrm{~h}$ after the last seizure.

Immunohistochemistry. A separate cohort of animals $(N=25 ; 2$ week implant study: naïve, $n=3$; pilocarpine, $n=4$; pilo + GDNF, $n=5 ; 12$ week implant study: naïve, $n=3$; pilocarpine, $n=4$; pilo + GDNF, $n=6$ ) was unilaterally implanted with GDNF devices $20 \mathrm{~d}$ after pilocarpineinduced SE. After either 2 or 12 weeks, rats were deeply anesthetized and transcardially perfused with $200 \mathrm{ml}$ of $0.9 \%$ ice-cold saline. Following saline perfusion, rats were decapitated and the devices removed. Brains were placed in Zamboni's fixative (catalog \#NC9335034, Thermo Fisher Scientific) for 1 week, then were embedded in paraffin. The 8- $\mu$ m-thick sections were cut coronally using a Leica RM2125RT microtome through the hippocampus ( -2.3 to $-5.8 \mathrm{~mm}$ from bregma; Paxinos and Watson, 2007). Sections were dewaxed and rehydrated as previously described (Paradiso et al., 2009): two 10 min washes in xylene (catalog \#1330-20-7, Sigma-Aldrich), $5 \mathrm{~min}$ in 100\% ethanol, $5 \mathrm{~min}$ in 95\% ethanol, $5 \mathrm{~min}$ in $80 \%$ ethanol, and then rehydration in distilled water for $5 \mathrm{~min}$. All antigens were unmasked using a commercially available kit (Unmasker; catalog \#T0010, Diapath), according to the manufacturer instructions. After washing in PBS, sections were incubated at room temperature with Triton X-100 (0.3\% in PBS; catalog \#9002-93-1, Sigma-Aldrich) for $10 \mathrm{~min}$, washed twice in PBS, and incubated with $5 \%$ bovine serum albumin and 
$5 \%$ serum of the species in which the secondary antibody was produced for $30 \mathrm{~min}$. Sections were incubated overnight at $4^{\circ} \mathrm{C}$ in a humid atmosphere with a primary antibody specific for the following: glial fibrillary acid protein (GFAP; mouse polyclonal, catalog \#AMAb91033, Atlas Antibodies; PRID:AB_2665775), 1:100; doublecortin (DCX; rabbit polyclonal; catalog \#3973S, Cell Signaling Technology; PRID:AB_2276960), 1:400; parvalbumin (mouse monoclonal; catalog \#235, Swant; PRID: AB_10000343), 1:100; phosphorylated receptor tyrosine kinase RET (rabbit polyclonal, catalog \#sc-20252-R, Santa Cruz Biotechnology; PRID: AB_2179766), 1:100; and neural cell adhesion molecule (NCAM; mouse monoclonal; catalog \#MAB5324, Millipore; PRID:AB:_11210572), 1:400. After 5 min rinses in PBS, sections were incubated with Triton (as above; $30 \mathrm{~min}$ ), washed in PBS, and incubated with a goat anti-mouse Alexa Fluor 594 (catalog \#A-11058, Invitrogen; PRID:AB_142540) or Alexa Fluor 488 (catalog \#A-21125, Invitrogen; PRID:AB_141593) secondary antibody (1:250) for mouse primary antibodies, or with a goat anti-rabbit, Alexa Fluor 488 (catalog \#A-11094, Thermo Fisher Scientific; PRID:AB_221544) or Alexa Fluor 594 secondary antibody (catalog \#A-11012, Invitrogen; PRID:AB_141359, 1:250) for rabbit primary antibodies, at room temperature for $3 \mathrm{~h}$. After staining, sections were washed in PBS, counterstained with $0.0001 \% 4^{\prime}, 6^{\prime}$-diamidino-2-phenylindole dihydrochloride (DAPI; catalog \#D1306, Thermo Fisher Scientific; PRID:AB_2629482) for $15 \mathrm{~min}$, and washed again before coverslipping. Omission of the primary antibody resulted in no specific staining.

Fluoro-Jade C staining. Slides were dewaxed and immersed for $5 \mathrm{~min}$ in a solution of $1 \%$ sodium hydroxide in $80 \%$ ethanol, then rinsed for $2 \mathrm{~min}$ in $70 \%$ ethanol, for $2 \mathrm{~min}$ in distilled water, and incubated in $0.06 \%$ potassium permanganate solution for $10 \mathrm{~min}$. Slides were then transferred for $20 \mathrm{~min}$ into a $0.001 \%$ solution of FJC (catalog \#AG325-30MG, Millipore) followed by three $1 \mathrm{~min}$ washes in distilled water. Slides were air dried on a slide warmer at $50^{\circ} \mathrm{C}$ for $5 \mathrm{~min}$ and cleared in xylene for 1 min. Coverslips were mounted using DPX (catalog \#06522, SigmaAldrich) mounting media.

Morphological analyses. Quantitation of FJC, DCX, GFAP, PV, NCAM, and pRET-positive cells was performed by an investigator who was blinded to the experimental condition, using a Leica DMRA2 Microscope. Sections were collected for each stain at $500 \mu \mathrm{m}$ intervals throughout the hippocampus ( -2.3 to $-5.3 \mathrm{~mm}$ relative to bregma; Paxinos and Watson, 2007), and the total numbers of immunopositive cells were counted bilaterally.

Hippocampal volumetry. FJC-stained sections were selected at three levels in the dorsal hippocampus $(-2.8,-3.3,-3.8 \mathrm{~mm}$ relative to bregma; $N=25$ ), and the area of the hippocampus was calculated (in square micrometers) on images obtained using the scan slide module of the MetaMorph software using a $6.3 \times$ objective. For volumetric analysis of the hippocampus, values were obtained by applying the formula $V=\frac{h}{3} \times\left(B_{\max }+b_{\min }+\sqrt{B_{\max } \times b_{\min }}\right)$, where $h=500 \mu \mathrm{m}$.

Statistical methods. Mixed-design ANOVAs were used to determine the effects of treatment, time, and any treatment $\times$ time interactions. Table 1 statistical analyses performed. Where appropriate, post hoc comparisons were conducted using $t$ test and Fisher's LSD test. Statistical analyses were performed using SPSS Statistics software (SPSS). All data were found to have a normal distribution, based on the Shapiro-Wilk test. In cases of the violation of the sphericity assumption, Huynh-Feldt corrected $F$ values are given. The $\alpha$ value was set at 0.05 , and exact $p$ values are reported for significant results (Greenwald et al., 1996). Mean values and SEMs were calculated for each group and were expressed as the percentage of the naive group to facilitate statistical and graphic comparisons.

\section{Results}

\section{Long-term encapsulated cell function and tissue levels of GDNF in normal rats}

GDNF-secreting devices were implanted in naive rats and retrieved at different time points $(1,2,4,8,16$, or 24 weeks after implantation). All implanted devices were easily retrieved from the brain with no host tissue adhering to the capsule wall. All implants were located within the hippocampus and remained intact, with no evidence that any capsule broke either in situ or during the retrieval procedure. Quantification of device output confirmed a robust and sustained secretion of GDNF from the implanted devices (Fig. 2A). Before implantation, devices secreted $277.59 \pm 10.72 \mathrm{ng} / \mathrm{d}$ GDNF. Explanted devices showed an initial increase in secretion peaking at $\sim 2-8$ weeks $(28,451.50 \pm$ $192.84 \mathrm{ng} / 24 \mathrm{~h}$ ), then tapering to a sustained amount that remained well above preimplant levels for the 6 months of analysis (Fig. 2A; $566.79 \pm 192.47 \mathrm{ng} / 24 \mathrm{~h}$ ). The continued delivery of GDNF to the hippocampus significantly elevated local tissue concentrations of GDNF in a manner that paralleled device secretion (Fig. 2B). Tissue levels of GDNF were highly increased within 1 week following implantation and reached peak levels at 2-8 weeks (53.74 $\pm 8.89 \mathrm{ng})$, gradually decreasing while remaining elevated for at least 6 months postimplantation $(9.04 \pm 2.82 \mathrm{ng})$.

The prolonged and elevated levels of GDNF within the hippocampus were not associated with any changes in body weight or general behavioral activity. Indeed, over the 6 months of observation all rats gained weight at a typical rate that was indistinguishable between intact rats and those implanted with GDNF devices (Fig. $2 C ; t_{(6)}=0.27 ; p=0.81$ ). Similarly, no differences were noted when animals were evaluated for time spent sleeping (Fig. $2 D ; U=15.50, z=-0.45 ; p=0.65)$, awake/inactive ( $U=$ $15.00, z=-0.51 ; p=0.65)$, or moving across the cage $(U=$ $15.50, z=-0.45 ; p=0.65)$.

\section{Seizures}

Short-term (10 d) intrahippocampal implantation of GDNF devices dramatically reduced the frequency of motor seizures in pilocarpine-treated rats. Before GDNF treatment (first $10 \mathrm{~d}$ after the first spontaneous seizure; i.e., 10-20 d after SE), rats exhibited $2.34 \pm 0.05$ motor seizures/d. Five to $15 \mathrm{~d}$ following implantation (i.e., $25-35 \mathrm{~d}$ after $\mathrm{SE}$ ), the frequency of motor seizures was reduced to $0.62 \pm 0.14$ seizures/d (Fig. $3 A$; main effect of treatment: $\left.F_{(1,8)}=189.16 ; p<0.001\right)$. This effect had a relatively rapid onset, as it was observed within the first week of implantation and was confirmed by the significant time $\times$ treatment interaction $\left(F_{(9,72)}=2.14 ; p=0.037\right)$. While the frequency of motor seizures was reduced by $\sim 75 \%$, their duration was not altered relative to preimplantation (Fig. $3 B ; t_{(8)}=1.29, p=0.23$ ). As expected, EEG monitoring detected a greater number of seizures (i.e., animals were experiencing nonmotor as well as motor seizures). Again, the frequency of EEG seizures was strongly reduced in animals implanted with GDNF devices compared with those implanted with nonmodified parental ARPE-19 cells (Fig. 4A), but their duration was identical in both groups (Fig. 4B). Representative EEG traces from nonmotor and motor seizures are shown in Figure 4, $C$ and $D$. The magnitude of GDNF secretion from explanted devices (Fig. 3C; preimplant, $252.28 \pm 7.34 \mathrm{ng} / 24 \mathrm{~h}$; postimplant, $2339.26 \pm 194.86 \mathrm{ng} / 24 \mathrm{~h}$ ) and the levels of GDNF within the tissue ( $41.17 \pm 3.69 \mathrm{ng}$; data not shown) were comparable to those observed in the intact, normal brain.

We then extended these observations to investigate longer lasting implantations and the postimplantation persistence of the effects. We implanted the devices as in the previous experiment, but left them in the brain much longer ( $90 \mathrm{~d}$ ), while monitoring seizures in the following two epochs: $5-15 \mathrm{~d}$ (as above) and 80-90 $\mathrm{d}$ postimplantation. We then retrieved the devices and continued monitoring for 20 additional days. We found that the reduction in seizure frequency increased in magnitude over time, from $84 \%$ at 5-15 d postimplantation to $93 \%$ in the same animals at $80-90$ 
Table 1. Effects of GDNF treatment on seizure frequency and histological analyses

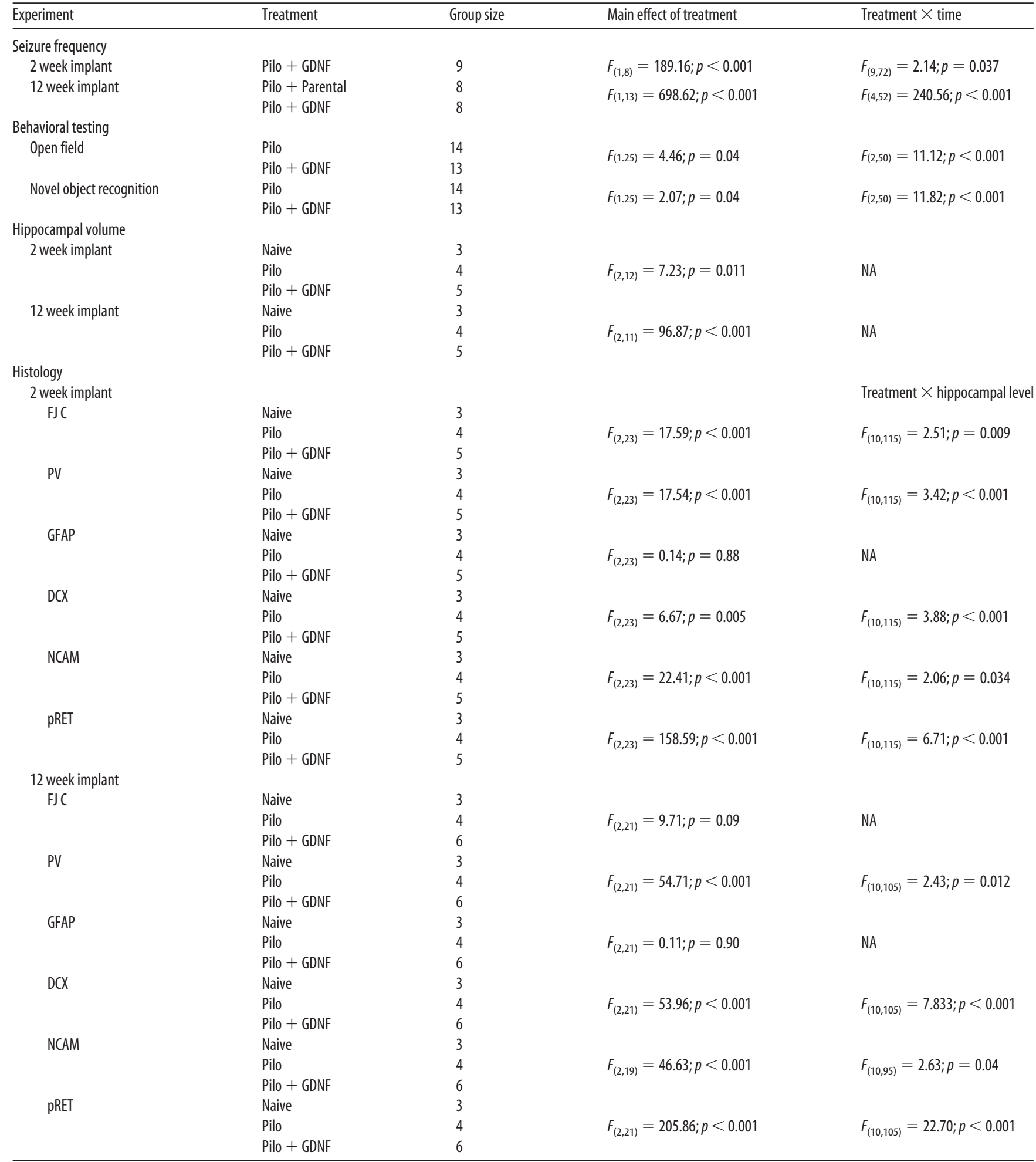

NA, Not applicable; Pilo, pilocarpine.

d postimplantation (Fig. $5 A ; F_{(1,13)}=698.62, p<0.001$ ). Implantation with control devices loaded with parental ARPE-19 cells did not alter seizure frequency at any time point. No change in seizure duration was observed at any time point in GDNF-treated animals and controls $\left(F_{(1,13)}=0.57 ; p=0.46\right)$.

Interestingly, a persistent effect was observed when the GDNF devices were retrieved $90 \mathrm{~d}$ following implantation (Fig. 5A). Although the frequency of spontaneous seizures did increase over preremoval values, it was still significantly lower than in control epileptic animals (65\% lower; Fig. 5A). Incidentally, it should be noted that, as previously reported (Soukupová et al., 2014), the frequency of seizures tended to increase in time in untreated animals.

At explant, the secretion of GDNF from devices remained high (Fig. 5B; preimplant, $283.36 \pm 8.82 \mathrm{ng} / 24 \mathrm{~h}$; postexplant, $4500.50 \pm 410.93 \mathrm{ng} / 24 \mathrm{~h}$ ). Relative to tissue levels measured 

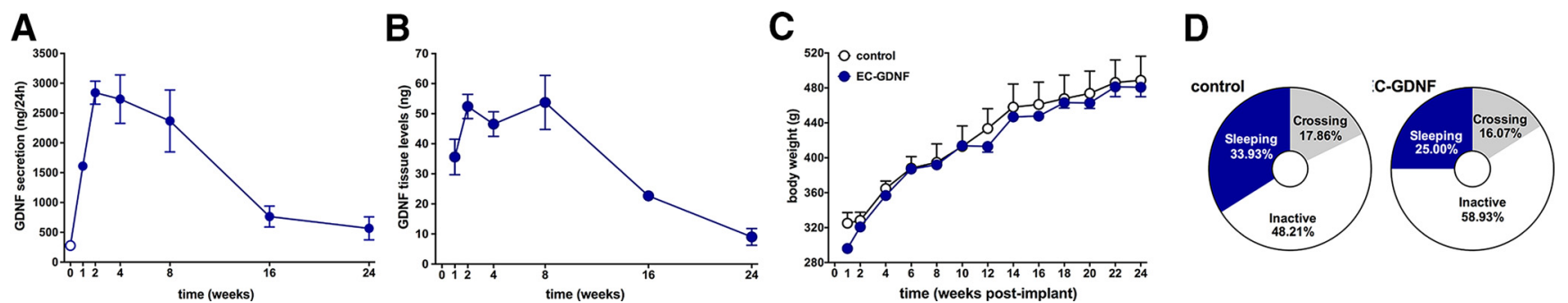

Figure 2. Encapsulated cell function, tissue levels of GDNF, body weight, and general behavioral activity in intact rats following bilateral intrahippocampal implantation of GDNF devices. $\boldsymbol{A}$, GDNF secretion from devices explanted from the hippocampus. Devices were implanted in intact rats and removed after 1,2,4,8, 16, and 24 weeks. GDNF secretion dramatically increased over preimplant values at 2-8 weeks and then slowly declined a sustained amount that remained above preimplant levels for the 6 months of analysis. $\boldsymbol{B}$, Hippocampal tissue levels of GDNF during device implantation. Tissue levels were elevated within 1 week, reached and maintained a peak at $2-8$ weeks, and then slowly decreased, remaining elevated for the duration of the experiment. $\boldsymbol{C}, \boldsymbol{D}$, Device implantation and elevation of tissue GDNF levels did not alter body weight $(\boldsymbol{C})$ or affect the general pattern of behavioral activity (D; Mann-Whitney $U$ test). All data are expressed as the mean \pm SEM of 4 animals per time point in $\boldsymbol{A}$ and $\boldsymbol{B}$, and 40 animals in $\boldsymbol{C}$ and $\boldsymbol{D}$.

A

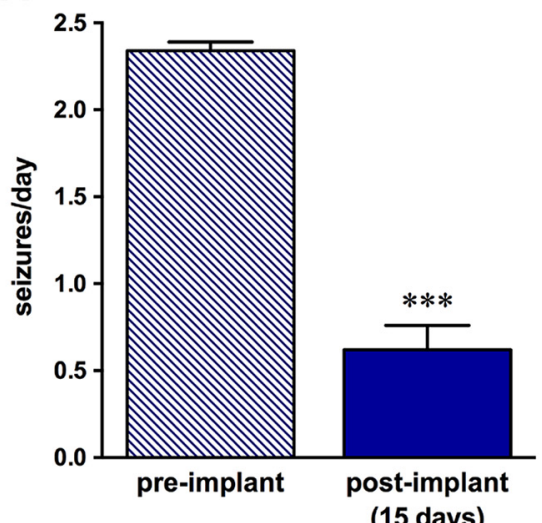

B

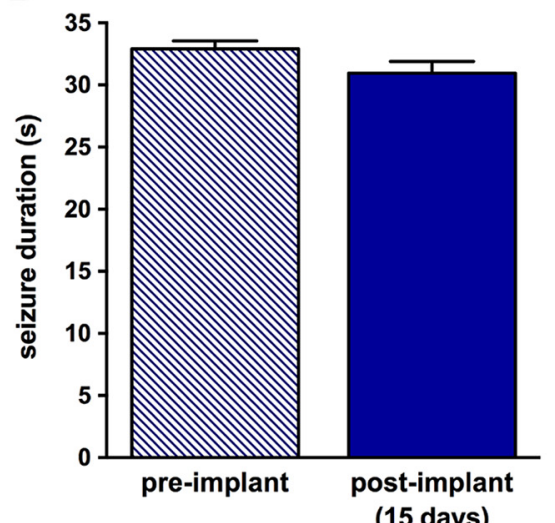

C

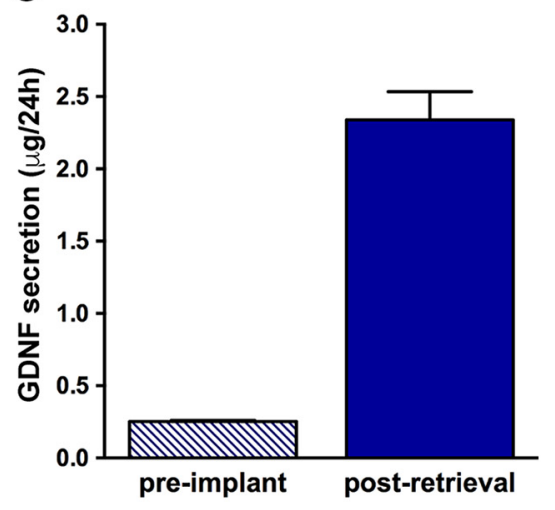

Figure 3. GDNF significantly reduces seizure frequency in pilocarpine-treated rats. Rats were video monitored before ( $10-20 \mathrm{~d}$ after SE) and following intrahippocampal GDNF device implantation (25-35 d after SE). $\boldsymbol{A}, \boldsymbol{B}$, The frequency of seizures was reduced by $84 \%$ relative to preimplantation levels $(\boldsymbol{A})$, whereas seizure duration was not altered ( $\boldsymbol{B})$. $\boldsymbol{C}$, Levels of GDNF secretion before implantation and after retrieval at the conclusion of the video monitoring. Data are the mean \pm SEM of nine animals monitored before and after GDNF treatment. ${ }^{* *} p<0.001$ based on paired $t$ test.

immediately after device retrieval, GDNF levels in the hippocampus were reduced by $>98 \%$ when quantified $20 \mathrm{~d}$ after device removal ( $1.57 \pm 1.01 \mathrm{ng}$; data not shown). This observation suggests that the persistent reduction in seizure frequency was not related to residual GDNF in the hippocampus.

\section{Open field and novel object recognition}

Pilocarpine-induced epilepsy produced significant impairments in the open-field and novel object recognition tests. Pilocarpinetreated rats alternated periods of hyperactivity and of freezing, spending significantly more time in the central part of the testing arena $\left(F_{(2,50)}=11.12 ; p<0.001\right)$. In contrast, GDNF treatment prevented the development of this phenotype, with treated rats performing comparably to naive ones (Fig. $6 A ; t_{(26)}=10.35 ; p=$ $0.004)$. Importantly, this change in behavior could not be attributed to alterations in general activity because, overall, the distance traveled and the immobility time did not change $\left(F_{(2,50)}=\right.$ $0.54, p=0.59$; and $F_{(2,50)}=0.05 ; p=0.95$; respectively; data not shown).

GDNF also reversed the cognitive impairment associated with pilocarpine-induced epilepsy. At baseline, all rats displayed a clear exploratory preference for the novel object, but this preference completely disappeared 4 weeks after SE $\left(F_{(2,50)}=11.82\right.$; $p<0.001)$. As shown in Figure $6 B$, pilocarpine-treated rats spent equal amounts of time exploring the new and the previously presented objects both 4 and 8 weeks after SE (i.e., 4 weeks after the implant of a control device; $\left.t_{(26)}=0.89 ; p=0.38\right)$. GDNF treatment reinstated the ability to distinguish between the novel and the familiar object (Fig. $6 B$; no GDNF: $t_{(13)}=1.33, p=0.21$; GDNF: $\left.t_{(12)}=7.07, p<0.001\right)$.

The findings described above were confirmed in the animals used for these behavioral experiments: the frequency of seizures was reduced by $74 \%$ relative to preimplantation $\left(t_{(8)}=13.66, p<\right.$ 0.001 ), and the magnitude of GDNF secretion was monitored preimplantation and after retrieval of the device from the hippocampus were $144.03 \pm 11.81$ and $3641.70 \pm 300.30 \mathrm{ng} / 24 \mathrm{~h}$, respectively.

\section{Immunohistochemistry}

\section{Neuroprotection}

To analyze the morphological effects of GDNF on the epileptic hippocampal tissue, we implanted a single device in one hippocampus $20 \mathrm{~d}$ after pilocarpine-induced SE, and sacrificed the rats 2 and 12 weeks thereafter. GDNF treatment exerted a pronounced neuroprotective effect, as evidenced by the quantitation of hippocampal volume, the counts of degenerating neurons, and the counts of parvalbumin-positive cells. These effects were observed at both 2 and 12 weeks postimplantation and were comparable in magnitude between both the implanted and nonimplanted hemispheres. A generalized atrophy of the hippocampus was observed in epileptic animals. Compared with naive controls, the hippocampal volume of pilocarpine-treated 


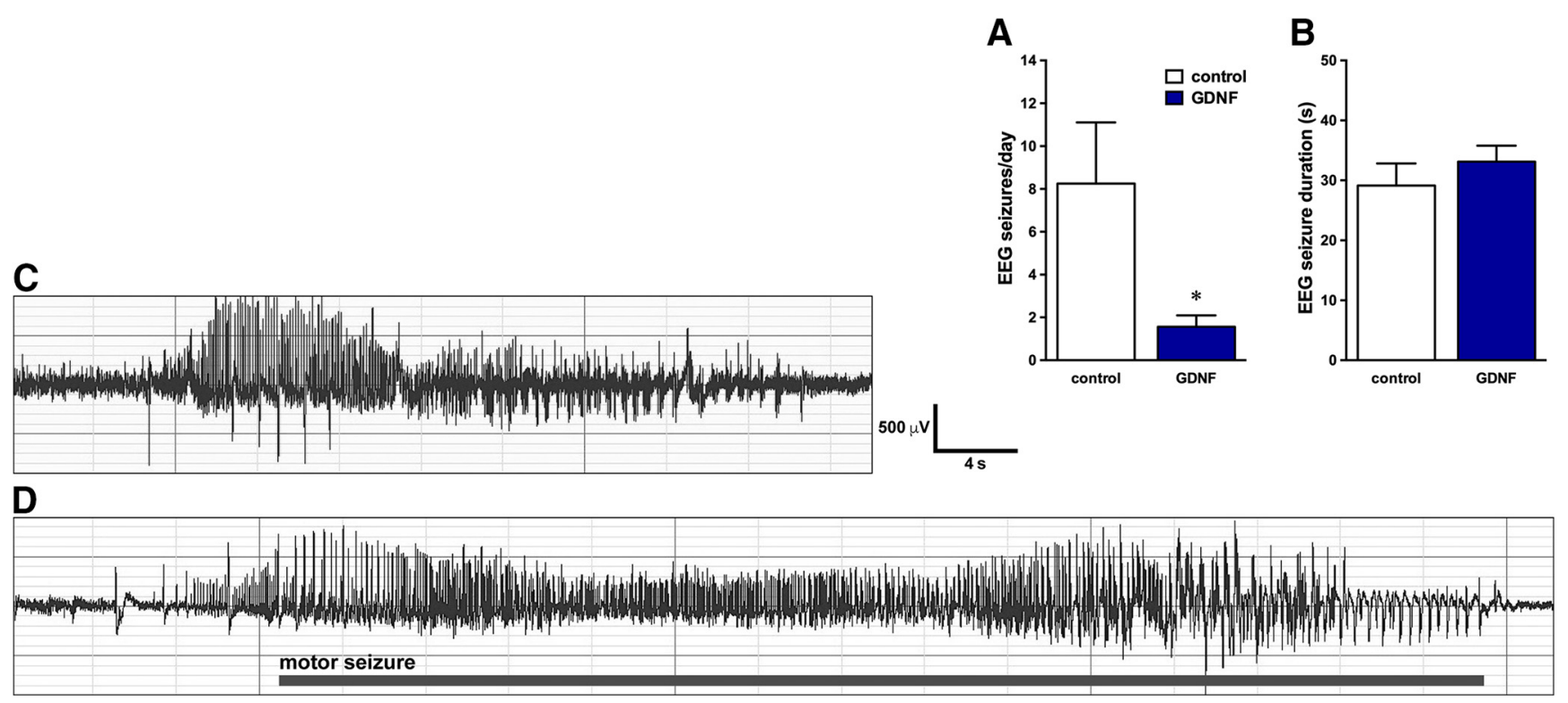

Figure 4. $\quad \boldsymbol{A}, \boldsymbol{B}$, Electrical seizure frequency $(\boldsymbol{A})$ and duration $(\boldsymbol{B})$ were recorded $5-15 \mathrm{~d}$ after implantation with the nonmodified parental ARPE-19 cells or GDNF devices in chronically epileptic animals. $\boldsymbol{C}, \boldsymbol{D}$, Representative EEG patterns in the hippocampus during nonmotor $(\boldsymbol{C})$ and motor $(\boldsymbol{D})$ seizures in GDNF device-implanted animals. Identical patterns were observed in animals implanted with empty devices. The horizontal bar in $\boldsymbol{D}$ indicates the motor part of the seizure. All data are expressed as the mean \pm SEM of seven animals per group. ${ }^{*} p<0.05$. Student's $t$ test for unpaired data.

A

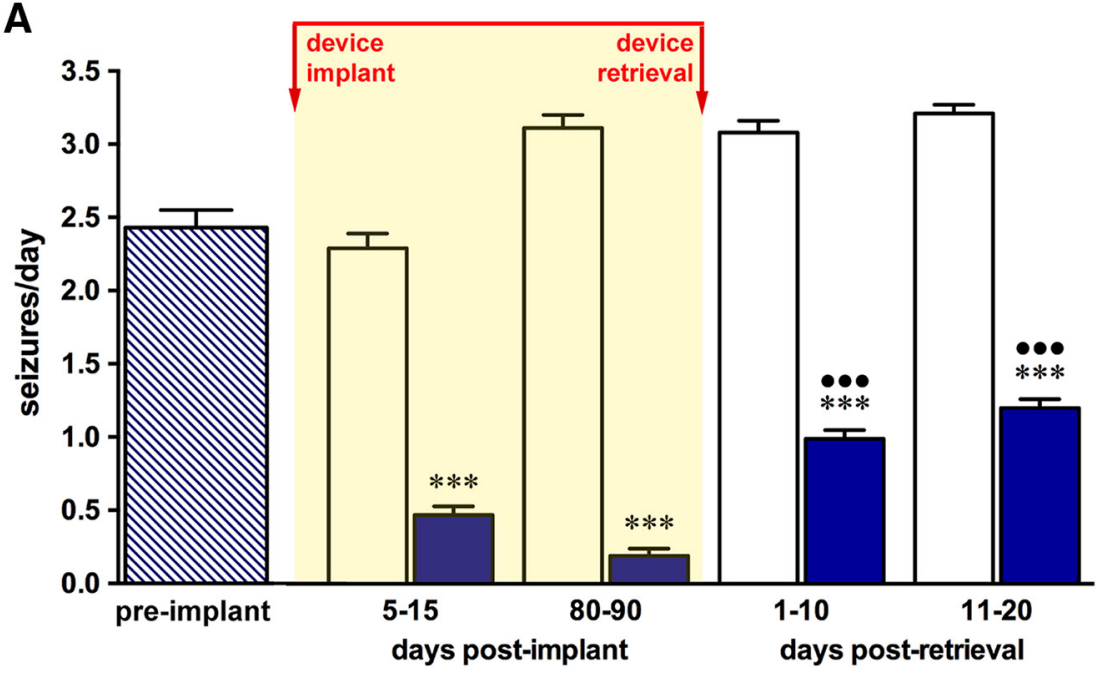

B

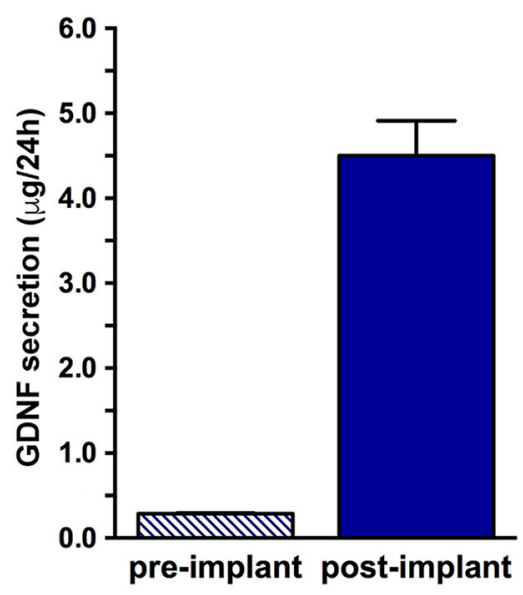

Figure 5. Long-term and persistent effects of GDNF on seizure frequency. Animals were implanted either with devices loaded with the nonmodified parental ARPE-19 cell line ( $N=8)$ or with GDNF-secreting devices $(N=8)$, as in Figure 3. A, Seizure frequency and duration were recorded before implantation ( $10-20 \mathrm{~d}$ after SE) and for two $10 \mathrm{~d}$ periods postimplantation (5-15 and 80 - 90 $\mathrm{d}$ after implantation; see text for details). At the conclusion of the second monitoring session (days 80 -90), devices were retrieved and animals were monitored for an additional $20 \mathrm{~d}$. Note that the effects of GDNF persisted even after device removal ( $65 \%$ decrease in seizure frequency relative to epileptic controls). $\boldsymbol{B}$, Levels of GDNF secreted before implantation and immediately following retrieval. All data are expressed as the mean \pm SEM of 16 animals ${ }^{* * *} p<0.001$ compared with control devices; $\bullet^{\bullet \bullet}<0.001$ compared with device preremoval values (80-90 d postimplant). Multiple comparisons were based on significant main effects or interactions resulting from the ANOVA described in the Materials and Methods and Results.

rats was reduced by $\sim 20 \% 2$ weeks after pilocarpine treatment, and by $33 \%$ after 12 weeks ( 2 weeks: $F_{(2,12)}=7.23 ; p=0.011 ; 12$ weeks: $F_{(2,11)}=96.87 ; p<0.001$; Figure 7$)$. Treatment with GDNF reversed this loss of hippocampal volume (Fig. 7).

FJC staining was used to identify degenerating neurons and to determine the ability of GDNF to attenuate damage (Ehara and Ueda, 2009) (Fig. 8). Quantitative analysis revealed a significant increase in degenerating cells in CA1, CA3, and hilus of the dentate gyrus following pilocarpine treatment compared with naive cells $(597 \%$ and $160 \%$ at 2 and 12 weeks after postpilocarpine treatment, respectively). Similar to the GDNF-induced prevention of hippocampal atrophy, a significant attenuation of neuro- nal degeneration was observed in treated rats, with a much smaller increase in FJC-positive cells (187\% and $32 \%$ at 2 and 12 weeks, respectively) compared with cells from naive animals $\left(F_{(2,23)}=17.59, p<0.001 ;\right.$ and $F_{(2,21)}=9.71, p=0.09$, respectively).

Finally, because epilepsy has been consistently linked to changes in GABAergic neurotransmission, including a loss of PV and somatostatin cells (Mazzuferi et al., 2010; Soukupová et al., 2014), we quantified the ability of GDNF to protect this cell population. As shown in Figure 9, pilocarpine significantly reduced the number of $\mathrm{PV}$-positive neurons in the hippocampus relative to naive rats (2 weeks: $F_{(2,23)}=17.54, p<0.001 ; 12$ weeks: 
A

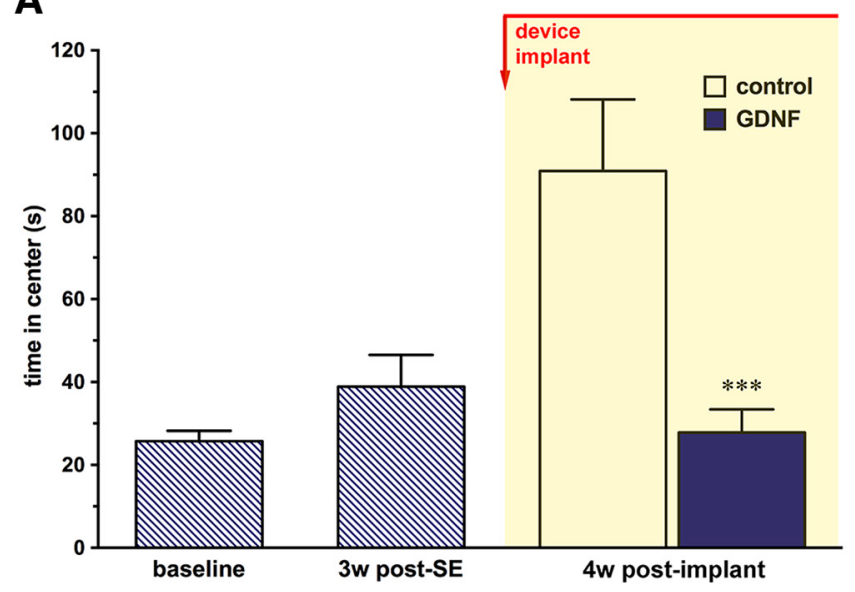

B

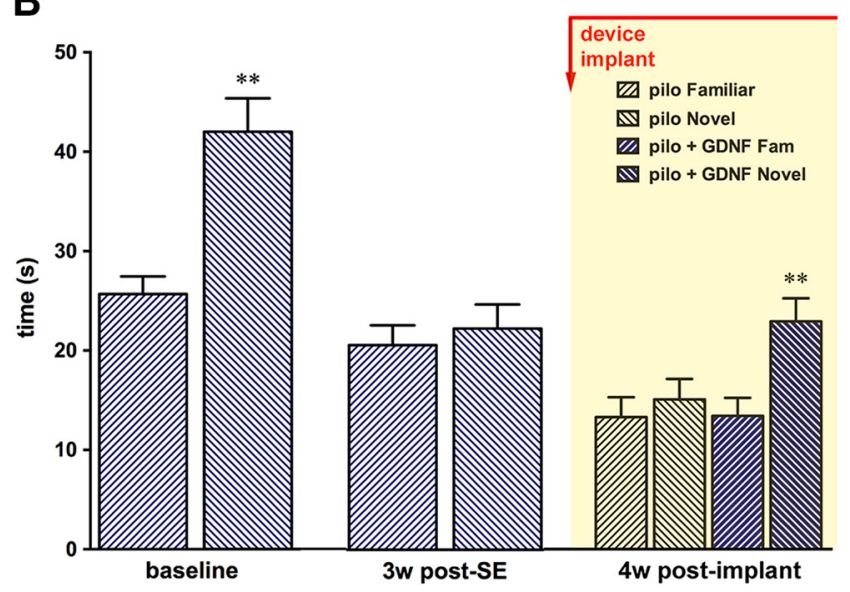

Figure 6. $\quad \boldsymbol{A}, \boldsymbol{B}$, Effect of GDNF in the open field $(\boldsymbol{A})$ and in the novel object recognition test $(\boldsymbol{B})$. Rats $(N=27)$ were tested before any manipulation (baseline) and 4 weeks after pilocarpine-induced SE. Following the post-pilocarpine test session, a subgroup of animals $(n=13)$ was implanted with GDNF devices. Pilocarpine-induced epilepsy progressively reduced the natural tendency of the rat to avoid the central region of the arena and the exploratory preference for the novel object. $A, B, G D N F$ restored a normal behavior both as measured by the time spent in the central region of the arena $(\boldsymbol{A})$ and as the ability to distinguish new from familiar objects $(\boldsymbol{B})$. All data are expressed as the mean \pm SEM. ${ }^{* *} p<0.01 ;{ }^{* * *} p<0.001$ of 27 animals. Multiple comparisons were based on significant main effects or interactions resulting from the ANOVAs described in the Materials and Methods and Results. w, Weeks.
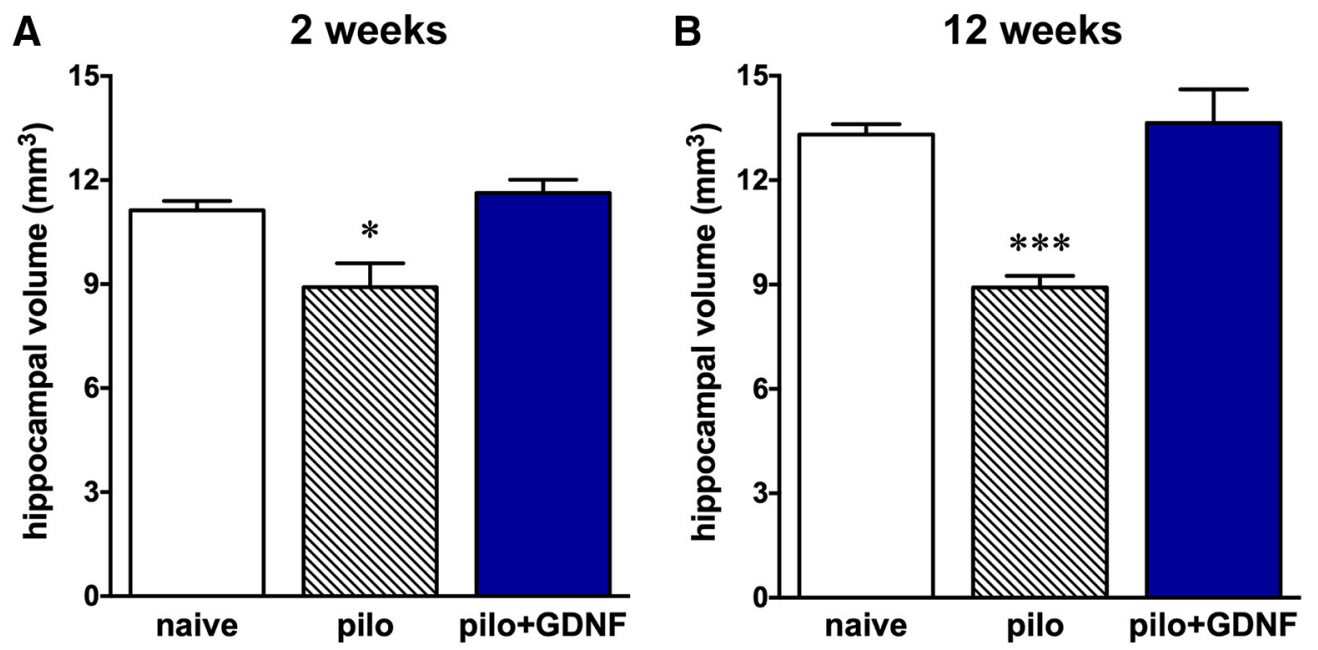

Figure 7. GDNF reverts the loss of hippocampal volume that occurs following pilocarpine. $A, B$, Sections were taken from the dorsal hippocampus of naive $(n=3)$, pilocarpine-treated $(n=4)$, and pilocarpine-treated rats treated with $\operatorname{GDNF}(n=5-6)$ for either for $2(\boldsymbol{A})$ or $12(\boldsymbol{B})$ weeks. Data are presented as absolute values of hippocampal volumes. Because no differences were noted between the right and left hemispheres in any group, data from both hemispheres were combined. All data are expressed as the mean \pm SEM. ${ }^{*} p<0.05$; ${ }^{* * *} p<0.001$ of 25 animals. Multiple comparisons were based on significant main effects resulting from the ANOVAs described in the Materials and Methods and Results. pilo, Pilocarpine.
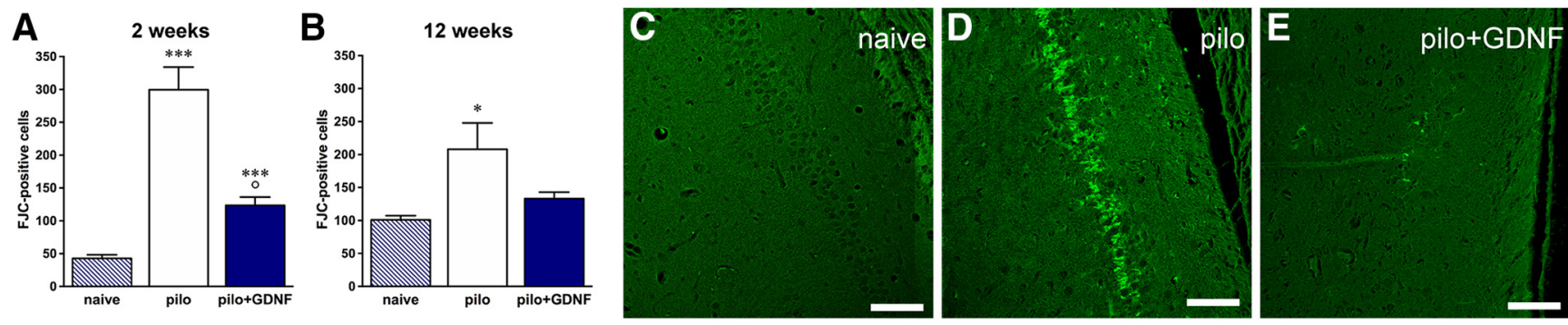

Figure 8. GDNF significantly reduces ongoing neuronal degeneration. $\boldsymbol{A}, \boldsymbol{B}$, The effects of pilocarpine and $2(\boldsymbol{A})$ or $12(\boldsymbol{B})$ weeks of treatment with GDNF on the total numbers of FJC-positive cells in the hippocampus. While pilocarpine significantly increased the numbers of degenerating FJC-positive neurons at both time points, this effect was significantly attenuated by GDNF. Data are expressed as the mean \pm SEM of three to six animals per group. ${ }^{*} p<0.05,{ }^{* * *} p<0.001$ vs naive; ${ }^{\circ} p<0.05$ vs pilo. Multiple comparisons were based on significant main effects resulting from the ANOVAs described in the Materials and Methods and Results. Representative images taken from naive, pilocarpine-treated, and pilocarpine-treated rats treated with GDNF at 2 weeks are shown in $\mathbf{C}-\mathbf{E}$. Scale bar, $500 \mu \mathrm{m}$. pilo, Pilocarpine. 

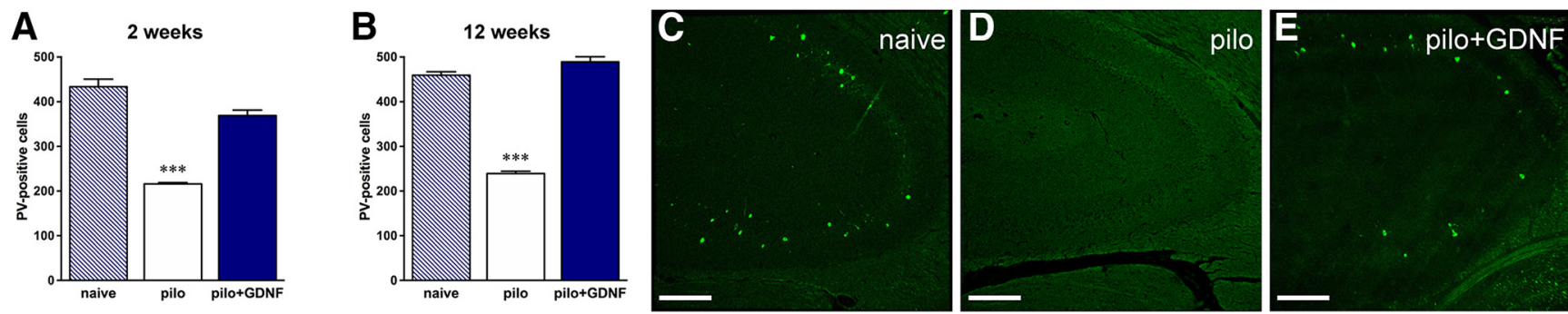

Figure 9. $\boldsymbol{A}, \boldsymbol{B}, \mathrm{GDNF}$ reverts pilocarpine (pilo)-induced degeneration of hippocampal parvalbumin (PV)-positive cells after both 2 weeks $(\boldsymbol{A})$ and 12 weeks $(\boldsymbol{B})$ of treatment. Data refers to the total number of positive cells and are expressed as the mean \pm SEM of three to six animals per group. ${ }^{* *} p<0.001$. Multiple comparisons were based on significant main effects resulting from the ANOVAs described in the Materials and Methods and Results. C-E, Representative images taken from the CA3 area of naive, pilocarpine-treated, and pilocarpine-treated rats treated with GDNF at 2 weeks are shown. Scale bar, $100 \mu \mathrm{m}$.
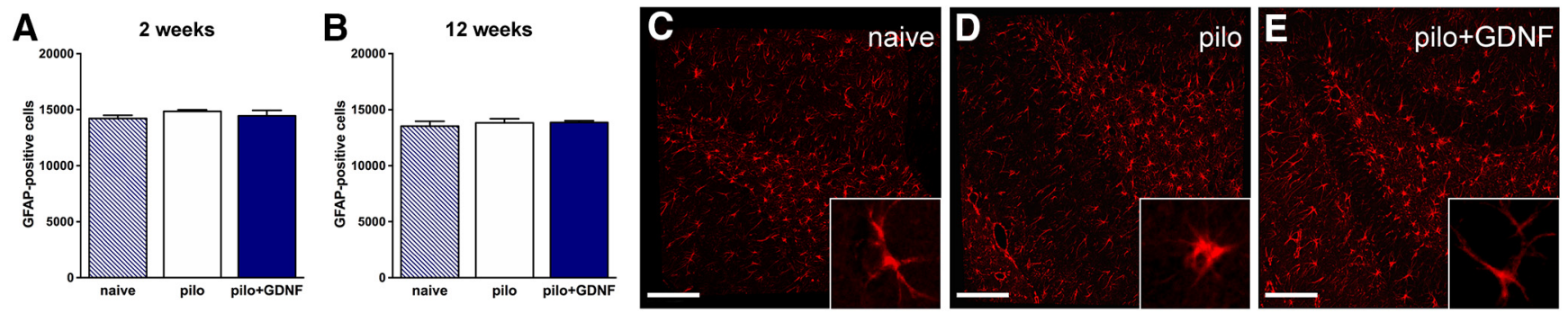

Figure 10. $\quad \boldsymbol{A}, \boldsymbol{B}$, Astrocyte density in the hippocampus is not altered by treatment with either pilocarpine or GDNF for $2(\boldsymbol{A})$ or $12(\boldsymbol{B})$ weeks. Data refer to the total number of positive cells and are expressed as the mean \pm SEM of three to six animals per group. $C-E$, Representative images taken from the hilus of the dentate gyrus area of naive, pilocarpine-treated, and pilocarpine-treated rats treated with GDNF at 2 weeks are shown. Scale bar, $100 \mu \mathrm{m}$. Higher-magnification inserts illustrate the changes in the morphology of GFAP-positive cells.
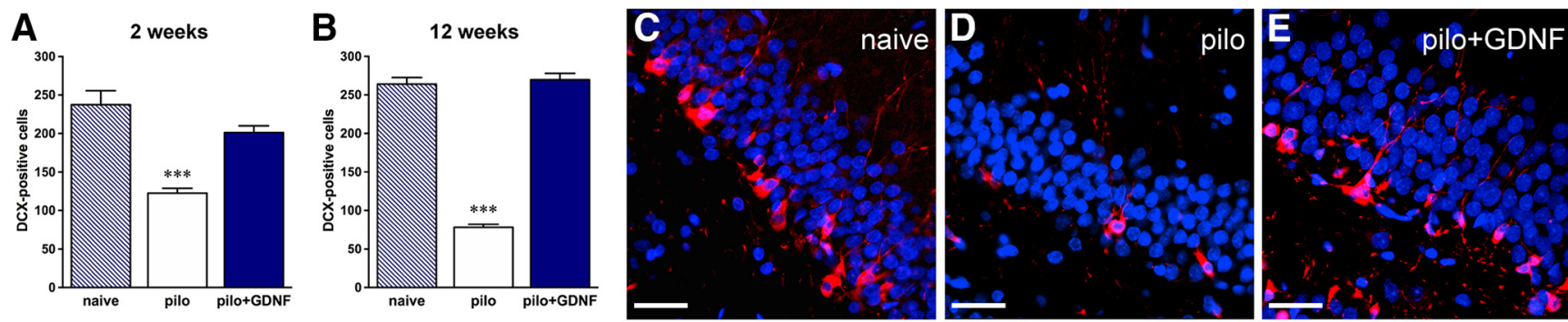

Figure 11. $\quad \boldsymbol{A}, \boldsymbol{B}, \mathrm{GDNF}$ normalizes neurogenesis after $2(\boldsymbol{A})$ and $12(\boldsymbol{B})$ weeks of treatment. Data refer to the total number of positive cells and are expressed as the mean \pm SEM of three to six animals per group. ${ }^{* * *} p<0.001$. Multiple comparisons were based on significant main effects resulting from the ANOVAs described in the Materials and Methods and Results. $\boldsymbol{C}-\boldsymbol{E}$, Representative DCX immunofluorescence (in red) images taken from the granular zone of the dentate gyrus of naive, pilocarpine-treated, and pilocarpine-treated rats treated with GDNF at 2 weeks are shown. Nuclei are marked by DAPI (blue). DCX-positive cells in the naive dentate gyrus are located in the subgranular zone and present notable elongations across the granular layer. Pilocarpine causes a decrease in DCX-positive cells, which is associated with fewer elongations in the remaining cells. Treatment with GDNF reverses the loss of DCX-positive cells and normalizes cellular morphology. Scale bar, $20 \mu \mathrm{m}$. pilo, Pilocarpine.

$\left.F_{(2,21)}=54.71, p<0.001\right)$. GDNF reversed this loss of PVpositive cells.

Epilepsy-associated astrocytosis was evaluated using GFAP immunofluorescence (Vezzani et al., 2000). The quantification of GFAP-positive cells revealed that treatment with neither pilocarpine nor GDNF in pilocarpine-treated animals altered the number of astrocytes (Fig. $10 A, B ; 2$ weeks: $F_{(2,23)}=0.14, p=$ 0.88 ; 12 weeks: $\left.F_{(2,21)}=0.11, p=0.90\right)$. However, many of the GFAP-positive cells in epileptic controls displayed short, thick processes, an indication of active astrocytosis (Fig. 10D, insert), whereas GFAP-positive cells of GDNF-treated rats were similar to those of naive animals, with a small cell body and thin processes (Fig. 10C,E, inserts).

\section{Neurogenesis}

As shown in Figure 11, GDNF treatment reversed the loss of DCX-positive cells that occurred following pilocarpine. In naive control rats, DCX-positive cells were present in the subgranular zone with notable elongations extending across the granular layer of the dentate gyrus region (Fig. 11C). In line with previous reports (Hattiangady et al., 2004), chronic epilepsy significantly decreased the numbers of these cells (by $48 \%$ and $70 \%$ at 2 and 12 weeks, respectively) and led to shorter and ectopic elongations. In contrast, treatment with GDNF restored the number of DCXpositive cells (2 weeks: $F_{(2,23)}=6.67, p=0.005 ; 12$ weeks: $\left.F_{(2,21)}=53.96, p<0.001\right)$. Qualitatively, these cells had their typical morphology with increased length and number of elongations, together with reduced cluster formation and reduced numbers of ectopic cells. The effects of GDNF were bilateral and more pronounced following 12 weeks of treatment.

\section{Target engagement}

Quantitative immunohistochemistry confirmed GDNF receptor engagement following GDNF device implantation. GDNF signals through a multicomponent receptor, first binding the Glycosylphosphatidylinisotol-anchored receptor $\alpha 1$ [GDNF family re- 
A

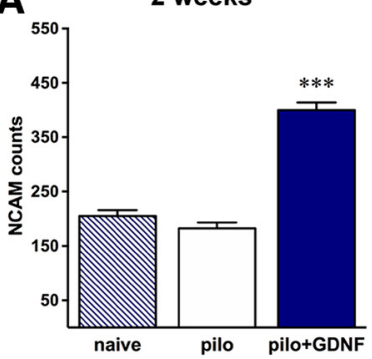

B

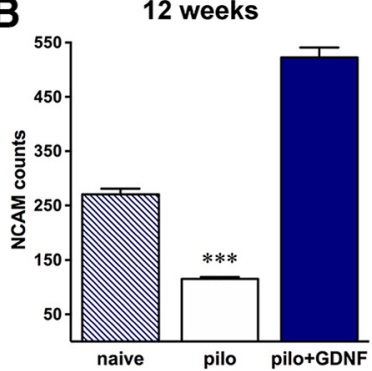

C

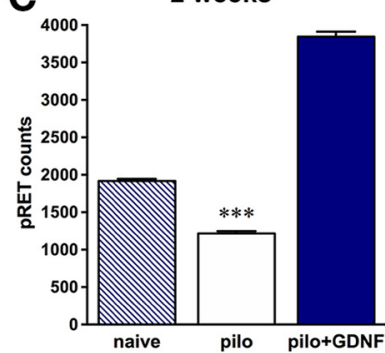

D

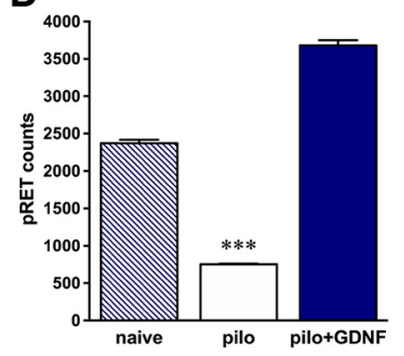

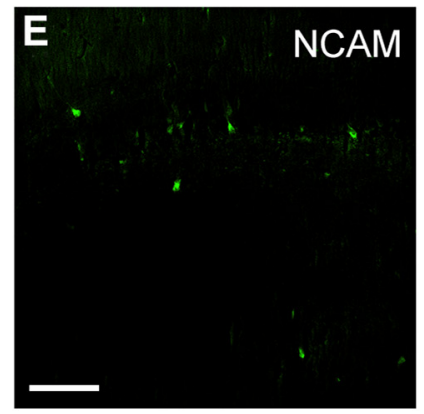
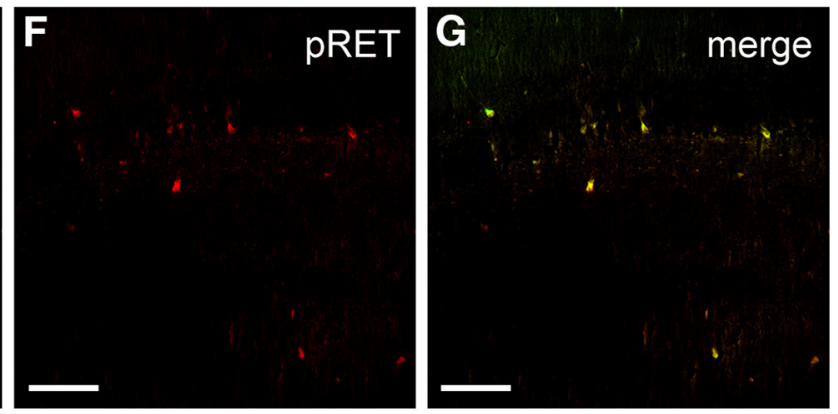

Figure 12. GDNF receptor engagement. $\boldsymbol{A}, \boldsymbol{B}$, Immunohistochemical quantification of NCAM expression after $2(\boldsymbol{A})$ or $12(\boldsymbol{B})$ weeks of GDNF treatment. Pilocarpine treatment significantly reduces the number of NCAM-positive cells at both time points. In contrast, GDNF increases NCAM expression above the levels observed in both the naive and pilocarpine-treated groups. $\boldsymbol{C}, \boldsymbol{D}$, Immunohistochemical quantification of phosphorylated Ret expression after $2(\boldsymbol{C})$ or $12(\boldsymbol{D})$ weeks of GDNF treatment. Pilocarpine treatment significantly reduces the number of pRet-positive cells at both time points. In contrast, GDNF increases pRET expression above the levels observed in both the naive and pilocarpine-treated groups. Data are expressed as the mean \pm SEM of three to six animals per group. ${ }^{* * *} p<0.001$. Multiple comparisons were based on significant main effects resulting from the ANOVAs described in the Materials and Methods and Results. $\boldsymbol{E}, \boldsymbol{F}$, Representative images of NCAM and pRET double staining in GDNF-treated animals are shown. $\mathbf{G}$, The merged image. Similar patterns (although quantitatively different) were observed in naive and pilocarpine-treated animals. pilo, Pilocarpine.

ceptor $\alpha 1$ (GFR $\alpha 1)$ ], with the resulting complex recruiting the transmembrane receptor tyrosine kinase Ret or the NCAM to initiate downstream activation of FAK (focal adhesion kinase) and FYN (proto-oncogene tyrosine-protein kinase) signaling pathways (Airaksinen and Saarma, 2002; Paratcha et al., 2006; Duveau and Fritschy, 2010). To explore the role of NCAMmediated GDNF effects on seizure frequency and neuroprotection, we quantified the numbers of NCAM-positive cells (Fig. $12 A, B)$. In line with previous studies (Ledergerber et al., 2006), we observed a decrease in NCAM-positive cells in the hippocampus of pilocarpine-treated animals at both 2 and 12 weeks compared with naive animals (12\% and 57\%, respectively). In contrast, NCAM expression was dramatically increased by GDNF treatment $\left(195 \%\right.$ at 2 weeks and $193 \%$ at 12 weeks: 2 weeks: $F_{(2,23)}$ $=22.41, p<0.001 ; 12$ weeks: $\left.F_{(2,19)}=46.63, p<0.001\right)$. A similar pattern was observed when the expression of phosphorylated Ret was assessed (Fig. 12C,D). Pilocarpine treatment significantly reduced the numbers of pRET-positive cells (by $37 \%$ and $68 \%$, respectively, 2 and 12 weeks following administration). GDNF treatment resulted in a marked increase (100\% and 55\%, respectively, after 2 and 12 weeks of treatment; 2 weeks: $F_{(2,23)}=$ 158.59, $p<0.001 ; 12$ weeks: $\left.F_{(2,21)}=205.86, p<0.001\right)$.

\section{Discussion}

Current pharmacological therapies for epilepsy are palliative at best, frequently produce adverse effects, and are commonly completely ineffective. There is, accordingly, an urgent need for novel therapies in the treatment of epilepsy. Neurotrophic factors such as GDNF may have the capacity to provide therapeutic benefits, and encapsulated cell technologies might be able to provide a safe means of selectively targeting and continuously delivering GDNF to the epileptic area (Lindvall and Wahlberg, 2008; EriksdotterJönhagen, 2012; Wahlberg et al., 2012; Orive et al., 2015). For these reasons, we engineered ARPE-19 cells to produce high levels of GDNF and enclosed them in a semipermeable capsule for implantation into the brain. The basic principle of this system is that the membrane allows oxygen and nutrients to enter and nourish the encapsulated cells while also allowing GDNF to leave the capsule and diffuse into the surrounding brain tissue, all the while eliminating exposure to the host immune system. This study provides important new data regarding the translation of this approach for continued development and human use. We report that GDNF devices can be implanted in the temporal lobe for prolonged periods of time while significantly elevating tissue levels of GDNF. The sustained delivery of GDNF was efficacious, as demonstrated by a pronounced and lasting reduction in seizure frequency. Importantly, nonmotor EEG seizure frequency was also reduced, indicating that the treatment actually suppresses seizures and does not merely attenuate their severity. This finding is in line with another study, in which we report that identical GDNF implants can also reduce the frequency of EEG seizures in the kainic acid model (Nanobashvili et al., 2018). In the present study, these favorable effects were rapid and progressive, with the seizure frequency reduced by $75 \%$ within 2 weeks after treatment and by $93 \%$ after 3 months of treatment. These effects are truly dramatic, considering that, in the pilocarpine model, only part of the seizures originates from the hippocampus (Toyoda et al., 2013). Therefore, this observation prompts the speculation that the hippocampus may also be implicated in seizures originating in other areas, and that treating the hippocampus may produce effects that surpass those expected (e.g., that the response to GDNF is nonlinear). The benefits of GDNF also appeared to extend beyond a simple symptomatic effect as it extended, even if in a less robust manner, well beyond removal of the devices. The concept of a potential disease-modifying effect is 
further supported by the observation that the reduction in seizure frequency was accompanied by improvements in cognition and anxiety, both significant comorbidities of epilepsy (Strzelczyk et al., 2017; Michaelis et al., 2018). These benefits occurred without classic signs of mistargeted neurotrophic factor delivery such as alterations in food consumption, changes in daily activity, or other overt neurobehavioral changes. The observation that GDNF alleviated behavioral alterations, an expression of comorbidities of pilocarpine-induced epilepsy, is of particular importance. Although these comorbidities are well known and can even predate the diagnosis of epilepsy itself, no effective treatment has yet been developed. Once spontaneous seizures begin to occur and the diagnosis of epilepsy is made, the disease often progresses with increased severity of seizures and the appearance of neurological impairments. The etiology underlying these comorbid changes in humans is complex and includes numerous factors, like age of onset, seizure type/severity/duration, use of antiepileptic medications, and neuroanatomical changes (Pitkänen and Sutula, 2002; Aldenkamp and Arends, 2004; Elger et al., 2004; Lin et al., 2012). These neurobehavioral changes can also be either chronic, as part of the underlying etiology of the disease itself, or in constant dynamic evolution, due to recurrent seizures and interictal spikes. The complex interplay of chronic and dynamic underlying mechanisms has made it difficult to develop therapies capable of treating the broad spectrum of behavioral deficits in epilepsy, and the data provided here suggest that direct CNS delivery of trophic molecules such as GDNF can, at least in part, fulfill this requirement. In fact, pilocarpine SE induces a progressive increase in seizure frequency as well as significant impairments in the normal exploratory behavior (Brandt et al., 2006; Tchekalarova et al., 2017; avoidance of open space) and in the ability of the rat to use learning and recognition memory capabilities (Ainge et al., 2007; Wood et al., 2000), and all these signs of disease are strongly attenuated by GDNF.

The potential disease-modifying benefits of GDNF might be explained, at least in part, by long-lasting anatomical adaptations. A number of morphological changes can occur in epilepsy, including overt cell loss, synaptic reorganization, and neurogenesis. First, we applied volumetric and immunohistochemical analyses to both confirm the effects of pilocarpine on cellular degeneration and investigate whether GDNF can alter this pattern (Niessen et al., 2005). Consistent with reports of morphological changes in hippocampal volume and shape in TLE (Van Paesschen et al., 1995; Bernasconi et al., 2003; Hibar et al., 2016), we found that pilocarpine-induced SE produced a severe loss in hippocampal volume together with neurodegeneration and astrocytosis. Treatment with GDNF reversed both of these pathological changes and also reversed the loss of GABAergic parvalbumin-positive hippocampal cells that was previously found to continue for weeks after pilocarpine-induced SE (Soukupová et al., 2014). The roles of GABAergic transmission in epilepsy are complex, with some data indicating that increases in GABAergic activity occur during the interictal phase and just before seizure onset (D'Antuono et al., 2004; Ellender et al., 2014; Yekhlef et al., 2015; de Curtis and Avoli, 2016). Elevated GABAergic activity leads to increased extracellular potassium, which supports hyperexcitability and epileptiform synchronization (Zuckermann and Glaser, 1968; Fertziger and Ranck, 1970; de Curtis and Gnatkovsky, 2009). On the other hand, there are studies suggesting that the impaired GABAergic inhibition, related to a selective loss of inhibitory interneurons, accounts for epileptiform activity (Wendling et al., 2002; Forte et al., 2016). Although electrophysiological validations are required, it is tempting to speculate that the normalization of GABAergic transmission by GDNF prevents the broad spatial hypersynchronous recruitment of neurons and interneurons observed at the transition from interictal to ictal activity (Schevon et al., 2012; Fujita et al., 2014). GDNF can also promote the functional and morphological differentiation of GABAergic neurons via GFR $\alpha 1$ (Pozas and Ibáñez, 2005; Paratcha et al., 2006; Perrinjaquet et al., 2011). Because defects in cortical GFR $\alpha 1$ signaling increase excitability and sensitivity to subthreshold doses of epileptogenic agents (Canty et al., 2009), it can be hypothesized that GDNF, via GFR $\alpha 1$ activation, restores inhibitory neurotransmission in epileptic animals by supporting the survival of GABAergic neurons. As brain insults can induce neurogenesis of GABAergic cells (Magnusson et al., 2014), it is possible that exogenous GDNFGFR $\alpha 1$ may redirect hippocampal granule cell neurogenesis after seizures toward inhibitory GABAergic cells (Marks et al., 2012).

The direct dependence of all the effects observed after GDNF treatment on GDNF receptors is difficult to assess with the currently available tools. Therefore, we attempted to at least demonstrate that the procedures led to target (GDNF receptor) engagement. To pursue this aim, we investigated the changes in NCAM and pRET. We found that GDNF reversed the decreased density of NCAM receptors and the expression of pRET in pilocarpine-treated animals, leading to levels well above those found in naive animals. These findings suggest a superactivation of GDNF receptors. In the adult hippocampal formation, NCAM is highly expressed in newly generated granule cells (Seki and Arai, 1993). The increased expression may reflect its role in regulating axonal outgrowth, synapse formation (Muller et al., 1996), and cell survival. The pattern was similar, with even more robust differences, when we assessed the expression of pRET. It has been previously reported that mRNA levels for GDNF and GDNF receptors (GFR $\alpha 1$ and RET) are region, cell, and insult specific (Reeben et al., 1998; Kokaia et al., 1999; Kanter-Schlifke et al., 2007). Here, we observe a robust increase of pRET expression indicating the activation of NCAM-independent GDNF signaling pathways.

The results described here form part of a program aimed at developing the use of polymer-encapsulated GDNF-secreting cells for direct and local delivery of GDNF to the brain of patients with epilepsy. These studies consistently demonstrated longterm and stable bioactive effects at doses shown to be safe in preclinical safety studies. To our knowledge, this is the first cellular delivery system capable of establishing the essential prerequisites of sustained, targeted, long-term delivery of sufficient quantities of GDNF to the temporal lobe. Based on the safety and efficacy of this platform technology, it represents a potentially novel and effective treatment for epilepsy.

\section{References}

Ainge JA, van der Meer MA, Langston RF, Wood ER (2007) Exploring the role of context-dependent hippocampal activity in spatial alternation behavior. Hippocampus 17:988-1002.

Airaksinen MS, Saarma M (2002) the GDNF family: signalling, biological functions and therapeutic value. Nat Rev Neurosci 3:383-394.

Aldenkamp A, Arends J (2004) The relative influence of epileptic EEG discharges, short nonconvulsive seizures, and type of epilepsy on cognitive function. Epilepsia 45:54-63.

Bernasconi N, Bernasconi A, Caramanos Z, Antel SB, Andermann F, Arnold DL (2003) Mesial temporal damage in temporal lobe epilepsy: a volumetric MRI study of the hippocampus, amygdala and parahippocampal region. Brain 126:462-469.

Brandt C, Gastens AM, Sun Mz, Hausknecht M, Löscher W (2006) Treatment with valproate after status epilepticus: effect on neuronal damage, 
epileptogenesis, and behavioral alterations in rats. Neuropharmacology 51:789-804.

Canty AJ, Dietze J, Harvey M, Enomoto H, Milbrandt J, Ibáñez CF (2009) Regionalized loss of parvalbumin interneurons in the cerebral cortex of mice with deficits in GFRalphal signaling. J Neurosci 29:10695-10705.

Curia G, Longo D, Biagini G, Jones RS, Avoli M (2008) The pilocarpine model of temporal lobe epilepsy. J Neurosci Methods 172:143-157.

D’Antuono M, Louvel J, Köhling R, Mattia D, Bernasconi A, Olivier A, Turak B, Devaux A, Pumain R, Avoli M (2004) GABAA receptor-dependent synchronization leads to ictogenesis in the human dysplastic cortex. Brain 127:1626-1640.

de Curtis M, Avoli M (2016) GABAergic networks jump-start focal seizures. Epilepsia 57:679-687.

de Curtis M, Gnatkovsky V (2009) Reevaluating the mechanisms of focal ictogenesis: the role of low-voltage fast activity. Epilepsia 50:2514-2525.

Duveau V, Fritschy JM (2010) PSA-NCAM-dependent GDNF signaling limits neurodegeneration and epileptogenesis in temporal lobe epilepsy. Eur J Neurosci 32:89-98.

Ehara A, Ueda S (2009) Application of fluoro-jade C in acute and chronic neurodegeneration models: utilities and staining differences. Acta Histochem Cytochem 42:171-179.

Elger CE, Helmstaedter C, Kurthen M (2004) Chronic epilepsy and cognition. Lancet Neurol 3:663-672.

Ellender TJ, Raimondo JV, Irkle A, Lamsa KP, Akerman CJ (2014) excitatory effects of parvalbumin-expressing interneurons maintain hippocampal epileptiform activity via synchronous afterdischarges. J Neurosci 34:15208-15222.

Ellinwood EH Jr, Balster RL (1974) Rating the behavioral effects of amphetamine. Eur J Pharmacol 28:35-41.

Emerich DF, Orive G, Thanos C, Tornoe J, Wahlberg LU (2014) Encapsulated cell therapy for neurodegenerative diseases: from promise to product. Adv Drug Deliv Rev 67-68:131-141.

Engel J Jr, McDermott MP, Wiebe S, Langfitt JT, Stern JM, Dewar S, Sperling MR, Gardiner I, Erba G, Fried I, Jacobs M, Vinters HV, Mintzer S, Kieburtz K (2012) Early surgical therapy for drug-resistant temporal lobe epilepsy: a randomized trial. JAMA 307:922-930.

Eriksdotter-Jönhagen M, Linderoth B, Lind G, Aladellie L, Almkvist O, Andreasen N, Blennow K, Bogdanovic N, Jelic V, Kadir A, Nordberg A, Sundström E, Wahlund LO, Wall A, Wiberg M, Winblad B, Seiger A, Almqvist P, Wahlberg L (2012) Encapsulated cell biodelivery of nerve growth factor to the basal forebrain in patients with Alzheimer's disease. Dement Geriatr Cogn Disord 33:18-28.

Fertziger AP, Ranck JB Jr (1970) Potassium accumulation in interstitial space during epileptiform seizures. Exp Neurol 26:571-585.

Fjord-Larsen L, Kusk P, Tornøe J, Juliusson B, Torp M, Bjarkam CR, Nielsen MS, Handberg A, Sørensen JC, Wahlberg LU (2010) Long-term delivery of nerve growth factor by encapsulated cell biodelivery in the Göttingen minipig basal forebrain. Mol Ther 18:2164-2172.

Fjord-Larsen L, Kusk P, Emerich DF, Thanos C, Torp M, Bintz B, Tornøe J, Johnsen AH, Wahlberg LU (2012) Increased encapsulated cell biodelivery of nerve growth factor in the brain by transposon-mediated gene transfer. Gene Ther 19:1010-1017.

Forte N, Medrihan L, Cappetti B, Baldelli P, Benfenati F (2016) 2-Deoxy-dglucose enhances tonic inhibition through the neurosteroid-mediated activation of extrasynaptic GABAA receptors. Epilepsia 57:1987-2000.

Fujita S, Toyoda I, Thamattoor AK, Buckmaster PS (2014) Preictal activity of subicular, CA1, and dentate gyrus principal neurons in the dorsal hippocampus before spontaneous seizures in a rat model of temporal lobe epilepsy. J Neurosci 34:16671-16687.

Greenwald AG, Gonzalez R, Harris RJ, Guthrie D (1996) Effect sizes and p values: what should be reported and what should be replicated? Psychophysiology 33:175-183.

Hattiangady B, Rao MS, Shetty AK (2004) Chronic temporal lobe epilepsy is associated with severely declined dentate neurogenesis in the adult hippocampus. Neurobiol Dis 17:473-490.

Hibar DP, Westlye LT, van Erp TG, Rasmussen J, Leonardo CD, Faskowitz J, Haukvik UK, Hartberg CB, Doan NT, Agartz I, Dale AM, Gruber O, Krämer B, Trost S, Liberg B, Abé C, Ekman CJ, Ingvar M, Landén M, Fears SC, et al (2016) Subcortical volumetric abnormalities in bipolar disorder. Mol Psychiatry 21:1710-1716.

Humpel C, Hoffer B, Strömberg I, Bektesh S, Collins F, Olson L (1994) Neurons of the hippocampal formation express glial cell line-derived neurotrophic factor messenger RNA in response to kainate-induced excitation. Neuroscience 59:791-795.

Kanter-Schlifke I, Georgievska B, Kirik D, Kokaia M (2007) Seizure suppression by GDNF gene therapy in animal models of epilepsy. Mol Ther 15:1106-1113.

Kanter-Schlifke I, Fjord-Larsen L, Kusk P, Angehagen M, Wahlberg L, Kokaia M (2009) GDNF released from encapsulated cells suppresses seizure activity in the epileptic hippocampus Exp Neurol 216:413-419.

Kilkenny C, Browne W, Cuthill IC, Emerson M, Altman DG (2011) Animal research: reporting in vivo experiments—-the ARRIVE guidelines. J Cereb Blood Flow Metab 31:991-993.

Kokaia Z, Airaksinen MS, Nanobashvili A, Larsson E, Kujamäki E, Lindvall O, Saarma M (1999) GDNF family ligands and receptors are differentially regulated after brain insults in the rat. Eur J Neurosci 11:1202-1216.

Kwan P, Brodie MJ (2000) Epilepsy after the first drug fails: substitution or add-on? Seizure 9:464-468.

Ledergerber D, Fritschy JM, Kralic JE (2006) Impairment of dentate gyrus neuronal progenitor cell differentiation in a mouse model of temporal lobe epilepsy. Exp Neurol 199:130-142.

Ledri LN, Melin E, Christiansen SH, Gøtzsche CR, Cifra A, Woldbye DP, Kokaia M (2016) Translational approach for gene therapy in epilepsy: model system and unilateral overexpression of neuropeptide $\mathrm{Y}$ and $\mathrm{Y} 2$ receptors. Neurobiol Dis 86:52-61.

Lidster K, Jefferys JG, Blümcke I, Crunelli V, Flecknell P, Frenguelli BG, Gray WP, Kaminski R, Pitkänen A, Ragan I, Shah M, Simonato M, Trevelyan A, Volk H, Walker M, Yates N, Prescott MJ (2016) Opportunities for improving animal welfare in rodent models of epilepsy and seizures. J Neurosci Methods 260:2-25.

Lin JJ, Mula M, Hermann BP (2012) Uncovering the neurobehavioural comorbidities of epilepsy over the lifespan. Lancet 380:1180-1192.

Lindvall O, Wahlberg LU (2008) Encapsulated cell biodelivery of GDNF: a novel clinical strategy for neuroprotection and neuroregeneration in Parkinson's disease? Exp Neurol 209:82-88.

Magnusson JP, Göritz C, Tatarishvili J, Dias DO, Smith EM, Lindvall O, Kokaia Z, Frisén J (2014) A latent neurogenic program in astrocytes regulated by notch signaling in the mouse. Science 346:237-241.

Marks C, Belluscio L, Ibáñez CF (2012) Critical role of GFR $\alpha 1$ in the development and function of the main olfactory system. J Neurosci 32:1730617320.

Mazzuferi M, Palma E, Martinello K, Maiolino F, Roseti C, Fucile S, Fabene PF, Schio F, Pellitteri M, Sperk G, Miledi R, Eusebi F, Simonato M (2010) Proc Natl Acad Sci U S A 107:3180-3185.

Michaelis R, Tang V, Wagner JL, Modi AC, Curt LaFrance W Jr, Goldstein LH, Lundgren T, Reuber M (2018) Cochrane systematic review and meta-analysis of the impact of psychological treatments for people with epilepsy on health-related quality of life. Epilepsia 59:315-332.

Muller D, Wang C, Skibo G, Toni N, Cremer H, Calaora V, Rougon G, Kiss JZ (1996) PSA-NCAM is required for activity-induced synaptic plasticity. Neuron 17:413-422.

Nanobashvili A, Melin E, Emerich D, Tornøe J, Simonato M, Wahlberg L, Kokaia M (2018) Unilateral ex vivo gene therapy by GDNF in epileptic rats. Gene Ther. Advance online publication. Retrieved November 21, 2018. doi: 10.1038/s41434-018-0050-7.

Niessen HG, Angenstein F, Vielhaber S, Frisch C, Kudin A, Elger CE, Heinze HJ, Scheich H, Kunz WS (2005) Volumetric magnetic resonance imaging of functionally relevant structural alterations in chronic epilepsy after pilocarpine-induced status epilepticus in rats. Epilepsia 46:1021-1026.

Nikitidou L, Torp M, Fjord-Larsen L, Kusk P, Wahlberg LU, Kokaia M (2014) Encapsulated galanin-producing cells attenuate focal epileptic seizures in the hippocampus. Epilepsia 55:167-174.

Nogueira MH, Yasuda CL, Coan AC, Kanner AM, Cendes F (2017) Concurrent mood and anxiety disorders are associated with pharmacoresistant seizures in patients with MTLE. Epilepsia 58:1268-1276.

Orive G, Santos E, Poncelet D, Hernández RM, Pedraz JL, Wahlberg LU, De Vos P, Emerich D (2015) Cell encapsulation: technical and clinical advances. Trends Pharmacol Sci 36:537-546.

Paradiso B, Marconi P, Zucchini S, Berto E, Binaschi A, Bozac A, Buzzi A, Mazzuferi M, Magri E, Navarro Mora G, Rodi D, Su T, Volpi I, Zanetti L, Marzola A, Manservigi R, Fabene PF, Simonato M (2009) Localized delivery of fibroblast growth factor-2 and brain-derived neurotrophic factor reduces spontaneous seizures in an epilepsy model. Proc Natl Acad Sci U S A 106:7191-7196. 
Paradiso B, Zucchini S, Su T, Bovolenta R, Berto E, Marconi P, Marzola A, Navarro Mora G, Fabene PF, Simonato M (2011) Localized overexpression of FGF-2 and BDNF in hippocampus reduces mossy fiber sprouting and spontaneous seizures up to 4 weeks after pilocarpine-induced status epilepticus. Epilepsia 52:572-578.

Paratcha G, Ibáñez CF, Ledda F (2006) GDNF is a chemoattractant factor for neuronal precursor cells in the rostral migratory stream. Mol Cell Neurosci 31:505-514.

Paxinos G, Watson C (2007) The rat brain in stereotaxic coordinates. Amsterdam: Elsevier Academic.

Perrinjaquet M, Sjöstrand D, Moliner A, Zechel S, Lamballe F, Maina F, Ibáñez CF (2011) MET signaling in GABAergic neuronal precursors of the medial ganglionic eminence restricts GDNF activity in cells that express GFR $\alpha 1$ and a new transmembrane receptor partner. J Cell Sci 124:2797-2805.

Pitkänen A, Sutula TP (2002) Is epilepsy a progressive disorder? prospects for new therapeutic approaches in temporal-lobe epilepsy. Lancet Neurol $1: 173-181$.

Pozas E, Ibáñez CF (2005) GDNF and GFRalphal promote differentiation and tangential migration of cortical GABAergic neurons. Neuron 45:701-713.

Racine RJ, Gartner JG, Burnham WM (1972) Epileptiform activity and neural plasticity in limbic structures. Brain Res. 47:262-268.

Reeben M, Laurikainen A, Hiltunen JO, Castrén E, Saarma M (1998) The messenger RNAs for both glial cell line-derived neurotrophic factor receptors, c-ret and GDNFRalpha, are induced in the rat brain in response to kainate-induced excitation. Neuroscience 83:151-159.

Schevon CA, Weiss SA, McKhann G Jr, Goodman RR, Yuste R, Emerson RG, Trevelyan AJ (2012) Evidence of an inhibitory restraint of seizure activity in humans. Nat Commun 3:1060.

Seki T, Arai Y (1993) Highly polysialylated neural cell adhesion molecule (NCAM-H) is expressed by newly generated granule cells in the dentate gyrus of the adult rat. J Neurosci 13:2351-2358.

Simonato M (2014) Gene therapy for epilepsy. Epilepsy Behav 38:125-130.

Simonato M, Bennett J, Boulis NM, Castro MG, Fink DJ, Goins WF, Gray SJ, Lowenstein PR, Vandenberghe LH, Wilson TJ, Wolfe JH, Glorioso JC (2013) Progress in gene therapy for neurological disorders. Nat Rev Neurol 9:277-291.

Soukupová M, Binaschi A, Falcicchia C, Zucchini S, Roncon P, Palma E, Magri E, Grandi E, Simonato M (2014) Exp Neurol 257:39-49.

Sridharan R (2002) Epidemiology of epilepsy. Curr Sci 82:664-670.

Stephen LJ, Brodie MJ (2000) Epilepsy in elderly people. Lancet 355:1441-1446.

Strzelczyk A, Griebel C, Lux W, Rosenow F, Reese JP (2017) The burden of severely drug-refractory epilepsy: a comparative longitudinal evaluation of mortality, morbidity, resource use, and cost using German health insurance data. Front Neurol 8:712.

Tchekalarova J, Atanasova D, Nenchovska Z, Atanasova M, Kortenska L, Gesheva R, Lazarov N (2017) Agomelatine protects against neuronal damage without preventing epileptogenesis in the kainate model of temporal lobe epilepsy. Neurobiol Dis 104:1-14.

Tornøe J, Torp M, Jørgensen JR, Emerich DF, Thanos C, Bintz B, FjordLarsen L, Wahlberg LU (2012) Encapsulated cell-based biodelivery of meteorin is neuroprotective in the quinolinic acid ratmodel of neurodegenerative disease. Restor Neurol Neurosci 30:225-236.

Toyoda I, Bower MR, Leyva F, Buckmaster PS (2013) Early activation of ventral hippocampus and subiculum during spontaneous seizures in a rat model of temporal lobe epilepsy. J Neurosci 33:11100-11115.

Van Paesschen W, Sisodiya S, Connelly A, Duncan JS, Free SL, Raymond AA, Grünewald RA, Revesz T, Shorvon SD, Fish DR (1995) Quantitative hippocampal MRI and intractable temporal lobe epilepsy. Neurology 45:2233-2240.

Vezzani A, Moneta D, Conti M, Richichi C, Ravizza T, De Luigi A, De Simoni MG, Sperk G, Andell-Jonsson S, Lundkvist J, Iverfeldt K, Bartfai T (2000) Powerful anticonvulsant action of IL-1 receptor antagonist on intracerebral injection and astrocytic overexpression in mice. Proc Natl Acad Sci U S A 97:11534-11539.

Wahlberg LU, Lind G, Almqvist PM, Kusk P, Tornøe J, Juliusson B, Söderman M, Selldén E, Seiger Å, Eriksdotter-Jönhagen M, Linderoth B (2012) Targeted delivery of nerve growth factor via encapsulated cell biodelivery in alzheimer disease: a technology platform for restorative neurosurgery. J Neurosurg 117:340-347.

Wendling F, Bartolomei F, Bellanger JJ, Chauvel P (2002) Epileptic fast activity can be explained by a model of impaired GABAergic dendritic inhibition. Eur J Neurosci 15:1499-1508.

Williams PA, White AM, Clark S, Ferraro DJ, Swiercz W, Staley KJ, Dudek FE (2009) Development of spontaneous recurrent seizures after kainateinduced status epilepticus. J Neurosci 29:2103-2112.

Wood ER, Dudchenko PA, Robitsek RJ, Eichenbaum H (2000) Hippocampal neurons encode information about different types of memory episodes occurring in the same location. Neuron 27:623-633.

Yekhlef L, Breschi GL, Lagostena L, Russo G, Taverna S (2015) Selective activation of parvalbumin-or somatostatin-expressing interneurons triggers epileptic seizure-like activity in mouse medial entorhinal cortex. J Neurophysiol 113:1616-1630.

Yoo YM, Lee CJ, Lee U, Kim YJ (2006) Neuroprotection of adenoviralvector-mediated GDNF expression against kainic-acid-induced excitotoxicity in the rat hippocampus. Exp Neurol 200:407-417.

Zuckermann EC, Glaser GH (1968) Hippocampal epileptic activity induced by localized ventricular perfusion with high-potassium cerebrospinal fluid. Exp Neurol 20:87-110. 